\title{
Regulation of Mouse Microglia Activation and Effector Functions by Bone Marrow-Derived Mesenchymal Stem Cells
}

\author{
Beáta Hegyi, Zsuzsanna Környei, ${ }^{1}$ Szilamér Ferenczi, ${ }^{3}$ Rebeka Fekete, ${ }^{2}$ Gyöngyi Kudlik, ${ }^{1,4}$ \\ Krisztina J. Kovács, ${ }^{3}$ Emília Madarász, ${ }^{2}$ and Ferenc Uher ${ }^{4}$
}

Mesenchymal stems or stromal cells (MSCs) are rare multipotent cells with potent regenerative and immunomodulatory properties. Microglial cells (MGs) are specialized tissue macrophages of the central nervous system (CNS) that continuously survey their environment with highly motile extensions. Recently, several studies have shown that MSCs are capable of reprogramming microglia into an "M2-like" phenotype characterized by increased phagocytic activity and upregulated expression of anti-inflammatory mediators in vitro. However, the precise polarization states of microglia in the presence of MSCs under physiological or under inflammatory conditions remain largely unknown. In this study, we found that MSCs induce a mixed microglia phenotype defined as Arg1-high, CD86-high, CD206-high, IL-10-high, PGE2-high, MCP-1/CCL2-high, IL-1ßmoderate, NALP-3-low, and TNF- $\alpha$-low cells. These MSC-elicited MGs have high phagocytic activity and antigen-presenting ability. Lipopolysaccharide is able to shape this microglia phenotype quantitatively, but not qualitatively in the presence of MSCs. This unique polarization state resembles a novel regulatory microglia phenotype, which might contribute to the resolution of inflammation and to tissue repair in the CNS.

\section{AU3 Introduction}

$\mathrm{M}$ ESENCHYMAL STEM CELLS (MSCs) are rare multipotent stromal cells with potent regenerative and immunomodulatory properties. They were originally isolated from the bone marrow (BM) [1] and later from multiple other tissues and organs [2-4]. Their capacity to differentiate into a number of mesodermal and extramesodermal lineages has initiated great interest in the use of these cells for the treatment of a wide variety of degenerative disorders $[5,6]$. Recently, however, it became clear that the mechanisms involved in the reparative effects of MSCs are mainly related to their trophic effects on other cells, as well as to their antiinflammatory and immunoregulatory activity [7]. It has been demonstrated that MSCs exert their immunomodulatory effects on multiple populations of T and B lymphocytes [8-

AU4 10], NK cells [11], and other leukocytes [10,12] through multiple mechanisms, including various soluble factors and/ or direct cell-cell contact. Important mediators secreted by MSCs are prostaglandin E2 (PGE2) [13,14], indolamine 2,3dioxygenase enzyme $[15,16]$, nitric oxide $[17,18]$, transforming growth factor-beta, and hepatocyte growth factor
$[8,19]$. In addition, MSCs have been shown to express the coinhibitory molecules B7-H1 and B7-H4 [20,21], the notch ligand Jagged-1[22], and galectin-1 [23] on their surface, which negatively interfere with immune responses. Furthermore, maximum anti-inflammatory and immunosuppressive effects can be evoked if MSCs are activated in a proinflammatory microenvironment by the presence of cytokines such as interferon-gamma, tumor necrosis factor-alpha (TNF- $\alpha$ ), and/or interleukin-1-beta (IL-1 $\beta$ ) [24,25]. In turn, MSCs seem to provide signals that stimulate the conversion of macrophages to an anti-inflammatory/regulatory phenotype [12,26,27].

Mononuclear phagocytes are now not only recognized as crucial cellular components of tissue repair and regeneration in each organ, but can also contribute to tissue damage. They can adopt a variety of functional phenotypes in response to environmental cues. The classical M1 and M2 (pro- and antiinflammatory, respectively) polarization states represent two ends of a functional spectrum of cell activation [28].

Under stress or injury, the activation of microglial cells (MGs), the resident mononuclear phagocytes within the central nervous system (CNS), can result in the production

\footnotetext{
${ }^{1}$ Laboratory of Molecular Cell Biology, Institute of Molecular Pharmacology, Research Center for Natural Sciences, Hungarian Academy of Sciences, Budapest, Hungary.

${ }^{2}$ Laboratory of Cellular and Developmental Neurobiology and ${ }^{3}$ Laboratory of Molecular Neuroendocrinology, Institute of Experimental Medicine, Budapest, Hungary.

${ }^{4}$ National Blood Service, Stem Cell Biology Unit, Budapest, Hungary.
} 
of pro-inflammatory mediators that are toxic to neurons and contribute to the pathology of many neurodegenerative diseases. In contrast, under normal physiological conditions, MGs serve an important role in immune surveillance and homeostasis within the CNS by continually surveying their microenvironment $[29,30]$. Therefore, modulating microglia polarization state may limit inflammation and tissue damage within the CNS

Recently, several studies have shown that MSCs are capable of reprogramming MGs into an "M2-like" phenotype characterized by increased phagocytic activity and upregulated expression of anti-inflammatory mediators in vitro. However, the precise polarization states of microglia in the presence of MSCs under physiological or inflammatory conditions remain largely unknown. In most studies, xenogenic experimental systems were used; that is, cocultures of human MSCs with mouse or rat MGs [26,31-33] and primary microglia were frequently replaced with neoplastic cell lines (BV2 or N9) [34-36] or with hippocampal slices [37]. Only two laboratories used autologous mouse [35] or rat [38] primary MGs and MSCs. The different experimental approaches may explain the sometimes conflicting results obtained by different groups.

Our recent work was focused on the in vitro interactions of autologous BM-derived MSCs with primary MGs. The surface phenotype, phagocytic activity, pro- and anti-inflammatory mediator secretion ability, and antigen-presenting capacity of resting and endotoxin-stimulated mouse MGs were studied in the presence or absence of mouse BM-derived MSCs. We found that MSCs elicit a mixed microglia phenotype characterized by anti-inflammatory activity but increased phagocytic and antigen-presenting ability. Lipopolysaccharide (LPS) is able to shape this MG phenotype quantitatively, but not qualitatively in the presence of MSCs enhancing proinflammatory mediator production while not inducing a typical M1 phenotype.

\section{Materials and Methods}

\section{Animals}

Adult (10-12 weeks old) C57BL/6 (H-2b) (National Institute of Oncology, Budapest, Hungary) and neonatal (1-3 days old) $\mathrm{CD} 1, \mathrm{C} 57 \mathrm{~B} 1 / 6$, and $\mathrm{CX} 3 \mathrm{CR} 1^{+/ \mathrm{GFP}}$ transgenic mice (on C57BL/6 background) (Institute of Experimental Medicine, Budapest, Hungary) were used according to the guidelines of the Animal Care and Use Committee of the National Blood Service (Budapest, Hungary). CX3CR1 ${ }^{+/ G F P}$ animals [39] were obtained from the European Mouse Mutant Archive (EMMA cx3cr1tm1Litt MGI:2670351) and backcrossed for more than 10 generations to $\mathrm{C} 57 \mathrm{Bl} / 6$.

\section{Isolation and culturing of MSCs}

We established MSC cultures from the BM of adult $\mathrm{C} 57 \mathrm{Bl} / 6\left(\mathrm{H}-2^{\mathrm{b}}\right)$ mice. The isolation and characterization of these cells were carried out according to Hegyi et al. [40]. Briefly, after the decapitation of the animals, mononuclear cells were isolated by flushing the femurs with complete medium $(\mathrm{CM})$ containing DMEM/Ham's F-12 medium (Invitrogen), 10\% fetal bovine serum, 5\% horse serum (Invitrogen), $50 \mathrm{U} / \mathrm{mL}$ penicillin, $50 \mu \mathrm{g} / \mathrm{mL}$ streptomycin (Sigma-Aldrich), and $2 \mathrm{mM}$ L-glutamine (Invitrogen) supplemented with heparin at a final concentration of $5 \mathrm{U} / \mathrm{mL}$. To remove tissue debris, the suspension was filtered through a $60 \mu \mathrm{m}$ nylon mesh. The obtained cells were washed twice in Hanks' balanced saline (Invitrogen) and plated in a $25-\mathrm{cm}^{2}$ flask (BD Falcon) at a density of 2 $4 \times 10^{6}$ cells $/ \mathrm{cm}^{2}$ in $\mathrm{CM}$. After incubation in a humidified $5 \% \mathrm{CO}_{2}$ incubator at $37^{\circ} \mathrm{C}$ for $72 \mathrm{~h}$, the nonadherent cells were removed by replacing the $\mathrm{CM}$; this process was then repeated every 3 days. The confluent adherent primary cultures were washed with cold Hanks' balanced saline, then dissociated in $0.25 \%$ Trypsin-EDTA solution (Invitrogen), and replated in $75 \mathrm{~cm}^{2}$ culture flasks at a dilution of 1:5. Cultures were regularly split after reaching confluency. Cultures after 8-15 passages were used for the experiments.

\section{Preparation of mixed glial cell cultures and isolation of microglia}

The preparation of mixed glial cell cultures and the isolation of microglia were carried out according to Saura et al. [41] with some modifications. The brains of neonatal (P1-P3) CD1 mice were isolated and then the meninges and choroid plexus were removed. The forebrain tissue was cut into $\mathrm{mm}^{3}$ size pieces and digested $\left(10 \mathrm{~min}, 37^{\circ} \mathrm{C}\right)$ by $0.05 \%$ trypsin in phosphate-buffered saline (PBS) containing $400 \mu \mathrm{g} / \mathrm{mL}$ DNAse (Sigma-Aldrich). Cells were suspended in $\mathrm{CM}$ without horse serum and seeded into poly-L-lysine (PLL) (Sigma-Aldrich)-coated Petri dishes (BD Falcon). At the 24th and 48th hours, the nonadherent cells were removed by a thorough washing of the surface with culture media. After 3 weeks of incubation, the mature mixed glial cultures were treated with $0.05 \%$ EDTAfree Trypsin solution for $2 \mathrm{~h}$ at $37^{\circ} \mathrm{C}$ whereupon layers containing predominantly astroglial cells floated up from the bottom of the dishes. After the removal of the astrogliarich floating cells, the remaining adherent microglia cells were washed off by incubation with $0.25 \%$ Trypsin/EDTA solution at $37^{\circ} \mathrm{C}$ for $10 \mathrm{~min}$. The obtained MGs were washed and re-seeded to PLL-coated plates in CM without horse serum.

\section{Flow cytometric analysis}

$1-2 \times 10^{5}$ cells were stained in FACS buffer (PBS with $0.5 \% \mathrm{v} / \mathrm{w}$ bovine serum albumin) for $20 \mathrm{~min}$ at $4{ }^{\circ} \mathrm{C}$ with monoclonal antibodies for Sca-1, CD11b, CD34, CD44, CD45, CD73, CD86, CD206, F4/80, Gr1, Ter119, and MHC-II purchased from BD Pharmingen. After incubation, samples were washed with FACS buffer and analyzed on an FACScan flow cytometer using CellQuest software (Becton Dickinson).

\section{In vitro stimulation of MGs}

MGs were seeded at $10^{5}$ cells $/ \mathrm{mL}$ in 24-well flat-bottom plates (BD Falcon) in CM with or without $10^{4} \mathrm{MSCs}$ in the presence or absence of $1 \mu \mathrm{g} / \mathrm{mL}$ LPS and cultured for $48 \mathrm{~h}$ at $37^{\circ} \mathrm{C}$. To investigate the effect of spatial separation, we prepared transwell experiments, where $10^{4}$ MSCs were plated into transwell chambers with $1 \mu \mathrm{m}$ pore-sized membrane suitable for 24-well plates (BD Falcone) and $10^{5}$ MGs were added into the lower compartment. 


\section{Immunocytochemical staining and cell area calculations}

$10^{5}$ MGs were incubated at $37^{\circ} \mathrm{C}$ for $48 \mathrm{~h}$ in the presence or absence of $10^{4} \mathrm{BM}$-derived MSCs and $/$ or $10 \mu \mathrm{g} / \mathrm{mL}$ LPS. The cultures were fixed with $4 \%$ paraformaldehyde in PBS solution at room temperature for $20 \mathrm{~min}$ and were then incubated with the cell surface marker Isolectin $\mathrm{B}_{4}$ (Sigma L-2140; biotin conjugated) diluted (1:500) overnight in PBS containing $5 \%$ fetal calf serum at $4^{\circ} \mathrm{C}$. For fluorescent detection, after washing with PBS, Alexa 488conjugated avidin (Invitrogen; 1:1,000) was used for $60 \mathrm{~min}$ at room temperature. The preparations were covered with bis-benzimidazole (Sigma-Aldrich) containing Mowiol (Merck $\mathrm{KGaA}$ ). For each individual culture, independent images $(n=15)$ of random fields of view were taken with a Nikon A1R confocal laser-scanning system built on a Ti-E inverted Nikon microscope, having a 0.45 NA $20 \times$ CFI Super Plan Fluor ELWD (Nikon GmbH) objective and NIS elements (Nikon) software. Cell number was calculated by counting bis-benzimide (Hoechst)-stained nuclei. Individual cell areas were measured by Zeiss AxioVision 4.8 software.

\section{Yeast phagocytosis of MGs}

Saccharomyces cerevisiae cells were heat inactivated by boiling for $30 \mathrm{~min}$ and then resuspended in PBS at the final concentration of $5 \times 10^{7}$ cell $/ \mathrm{mL}$. From this solution, $0.1 \mathrm{~mL}$ $\left(5 \times 10^{6}\right.$ yeast cells $)$ was added to the wells containing microglia and/or MSCs and incubated at $37^{\circ} \mathrm{C}$ for $1 \mathrm{~h}$. Subsequently, noningested yeast cells were removed by repeated washing with PBS, and the cultures were fixed with $8 \%$ formalin (v/v in PBS) solution for $10 \mathrm{~min}$. After three additional washes with PBS, Giemsa solution was added to the specimens for $1 \mathrm{~h}$. Then, we took images of 10 random microscopic fields per sample using a $20 \times$ objective of an Olympus CK2 inverted microscope (Olympus) and a Nikon Coolpix 4500 digital camera (Nikon). In the photographs, the number of incorporated yeast particles by single MGs were counted $(n=100$ in each experimental group). Averages and standard deviations were calculated, and the significance was estimated by Student's $t$-test.

\section{Phagocytosis of apoptotic thymocytes by MGs}

Thymuses were obtained from 10 to 12 week-old C57BL/ 6 mice and minced to get a single cell suspension. To induce apoptosis, cells were incubated in CM supplemented with $2 \mu \mathrm{M}$ dexamethasone (Sigma-Aldrich) at a concentration of $5 \times 10^{6}$ cells $/ \mathrm{mL}$ for $8 \mathrm{~h}$. After washing, $5 \times 10^{6}$ thymocytes were added to the wells containing microglia and/or MSCs and incubated for an additional $48 \mathrm{~h}$ at $37^{\circ} \mathrm{C}$.

\section{Detection of secreted proteins in cell culture supernatants}

The amounts of CCL2 [monocyte chemoattractant protein-1 (MCP-1)], TNF- $\alpha$, IL-1 $\beta$, IL-10, and PGE2 in various cell culture supernatants were measured with ParameterTM quantitative ELISA Kits (R\&D Systems, Inc.) that were specific for the respective cytokine. Mouse arginase 1 ELISA Kit was obtained from the Hölzel Diagnostika $\mathrm{GmbH}$. The experiments were carried out according to the supplier's instructions.

\section{Quantitative real-time polymerase chain reaction}

Total RNA was isolated with GeneAid Total RNA Mini Kit from microglia and MSC mono-cultures and from MG/ MSC cocultures at $5 \mathrm{~h}$ after plating. The purity of RNA samples was checked, and concentrations were determined by a Nano Drop 2000 spectrophotometer (Thermo Scientific). One hundred fifty nanograms of RNA samples were converted to cDNA with High-Capacity cDNA Reverse Transcription Kit (Applied Biosystems). Real-time polymerase chain reaction (PCR) was performed with Power SYBR Green PCR Master Mix (Applied Biosystems) on ABI StepOne instrument according to the manufacturer's instructions. Primer sequences were designed by Primer Express 3.0 software:

GAPDH:

(f) TGACGTGCCGCCTGGAGAAA;

(r) AGTGTAGCCCAAGATGCCCTTCAG

TNF- $\alpha$ :

(f) CAGCCGATGGGTTGTACCTT

(r) GGCAGCCTTGTCCCTTGA

IL-10:

(f) AGTGAGAAGCTGAAGACCCTCAGG

(r) TTCATGGCCTTGTAGACACCTTGGT

IL-1 $\beta$ :

(f) TTGACGGACCCCAAAAGATG

(r) TGGACAGCCCAGGTCAAAG

NLRP3:

(f) CAGAGCCTACAGTTGGGTGAA

(r) ACGCCTACCAGGAAATCTCG

Arg1:

(f) GTCTGGCAGTTGGAAGCATCT

(r) GCATCCACCCAAATGACACA

MCP-1:

(f) CCAGCACCAGCACCAGCCAA

(r) TGGATGCTCCAGCCGGCAAC

Gene expression was analyzed by ABI StepOne program. GAPDH was used as an internal control. To confirm the identity of PCR products, a melting curve analysis had been performed with StepOne instrument's Software v.2.0.

\section{Antigen presentation}

For testing the effect of MSCs on the antigen presentation of MGs toward T cells, $10^{4} \mathrm{MSCs}, 10^{5} \mathrm{MGs}$, and $2 \times 10^{5}$ in vivo primed $\mathrm{T}$ cells were cultured along with different concentrations of ovalbumin (OVA) in the indicated combinations (see Results section) at $37^{\circ} \mathrm{C}$ for 5 days. T cells were obtained from the lymph nodes of $\mathrm{C} 57 \mathrm{Bl} / 6$ mice at 7 days after a subcutaneous injection of a mixture of complete Freund's adjuvant and OVA (in a ratio of 1:1). After the incubation, cultures were pulsed with $1 \mathrm{mCi}{ }^{3} \mathrm{H}$-thymidine (Amersham) for $18 \mathrm{~h}$. Cells were harvested, and thymidine incorporation was quantified in counts per minute $(\mathrm{cpm} \pm \mathrm{SD} ; n=3)$. The amount of regulatory T cells was determined by FACS using the Mouse Regulatory T-Cell Staining Kit \#1 (eBioscience).

\section{T-cell proliferation}

$5 \times 10^{4}$ MSCs were seeded in 96-well flat-bottom plates (BD Falcon) and cultured for $24 \mathrm{~h}$ at $37^{\circ} \mathrm{C}$. After $24 \mathrm{~h}$, 
nonadherent cells were washed off. To isolate $\mathrm{T}$ lymphocytes, splenocytes derived from adult $\mathrm{C} 57 \mathrm{Bl} / 6(\mathrm{H}-2 \mathrm{~b})$ and $\mathrm{Balb} / \mathrm{c}$ $(\mathrm{H}-2 \mathrm{~d})$ mice were isolated by disaggregation of spleens; then, erythrocytes were depleted by $\mathrm{NH}_{4} \mathrm{Cl}$ lysis $\left(0.15 \mathrm{M} \mathrm{NH} \mathrm{N}_{4} \mathrm{Cl}\right.$ in $0.01 \mathrm{M}$ Tris- $\mathrm{HCl}$ buffer, $\mathrm{pH}=7.5$ ). To purify $\mathrm{T}$ lymphocytes, SpinSep Mouse CD3+ T-Cell Enrichment Kits were used according to the manufacturer's protocol (Stem Cell Technologies). In mitogen-driven proliferation assays, $10^{6} \mathrm{~T}$ lymphocytes ( $>95 \% \mathrm{CD}^{+}$cells by flow cytometry) were seeded in $200 \mu \mathrm{L} \mathrm{CM}$ in the presence of $5 \mu \mathrm{g} / \mathrm{mL}$ concanavalin $\mathrm{A}$ (ConA; Sigma-Aldrich) $(n=3) .2-3 \times 10^{5}$ responder and 2 $3 \times 10^{5}$ irradiated $(30 \mathrm{~Gy})$ stimulator splenocytes per well were seeded in a total volume of $200 \mu \mathrm{L}$ medium to prepare mixed lymphocyte reactions (MLR). After an incubation of 2 (for mitogen-driven cultures) or 4 (for MLR) days, cultures were pulsed with $1 \mu \mathrm{Ci}{ }^{3} \mathrm{H}$-thymidine (Amersham Pharmacia Biotech Export $\mathrm{GmbH}$ ) for $8 \mathrm{~h}$. Thymidine incorporation of harvested cells was measured in a Packard Tricarb beta counter (Perkin-Elmer), to indicate proliferation in cpm. Results were expressed as mean values \pm SD.

\section{Statistical analysis}

Data are expressed as mean $\pm \mathrm{SD}$. The differences between groups were evaluated by a two-tailed Student's $t$ test. The significance level was set at $P<0.05$.

\section{Results}

\section{Characterization of MSCs and MGs}

MSCs derived from the $\mathrm{BM}$ of adult $\mathrm{C} 57 \mathrm{~B} 1 / 6$ mice were positive for MSC markers (Sca-1, CD44, and CD73), but negative for several hematopoietic markers (CD34, CD45, CD11b, F4/80, Gr1, Ter119, and CD206), and could differentiate into adipocytes and osteoblasts in vitro (data not shown), as previously described $[40,42]$.

The majority $(70 \%-80 \%)$ of cultured MGs derived from neonatal CD1 or C57B1/6-CX3CR1 ${ }^{+/ G F P}$ mice were positive for F4/80, a marker for murine microglia, and partially positive for CD11b and CD206. However, only a very low level of MHC class II antigen expression was observed on the surface of MGs, indicating that they are mainly in

F1 resting state (Fig. 1A). The identity of MGs was further AU5 confirmed by a yeast phagocytosis assay (see below).

\section{MSCs induce morphological and functional changes in microglia}

To test whether MSCs can induce morphological changes of MGs, cocultures of MGs with MSCs (ratio=10:1) were established. The shape, size, and phagocytotic activity of MGs were compared between pure MG cultures and MSCMG cocultures. In mono-type cultures, the majority of

SF1 MGs (Supplementary Fig. S1A, C; Supplementary Data are available online at www.liebertpub.com/scd) had a rather small, compact perikaryon with thin, ramifying processes; whereas in the presence of MSCs, they displayed an enlarged, flattened cell shape with thick irregular protrusions (Supplementary Fig. S1B, D). Next, we repeated the coculture experiment using GFP-positive MGs derived from C57B1/6-CX3CR1 +/GFP mice (Supplementary Fig. S1E, F). To quantify this difference, the size of the MGs in the cul- tures were determined in images taken with a Nikon A1R confocal laser-scanning system with the help of Zeiss AxioVision 4.8 software after Isolectin-B4 staining. As shown in Fig. 1B and Supplementary Fig. S1C and D, the average size of MGs almost doubled in the presence of MSCs $(1,682 \pm 74$ vs. $2,858 \pm 101, n=3, P<0.001)$ compared with MGs cultured alone.

Furthermore, the presence of MSCs markedly increased the yeast phagocytosis of microglia (Fig. 1C and Supplementary Fig. S2A, B). Since the recognition of yeast cells involves a number of receptors, including the CD206 mannose receptor, we analyzed the expression of CD206 on the surface of MGs in the presence or absence of MSCs. We found that, after $48 \mathrm{~h}$ of coculturing with MSCs, the expression of CD206 significantly increased in F4/80-positive MGs compared with microglia cultured alone $(45.1 \% \pm 2.8 \%$ vs. $34.9 \% \pm 3.1 \%, n=5, P<0.001$ ) (Fig. 1D).

The release of pro- and anti-inflammatory mediators by MGs was assessed after yeast cell and apoptotic thymocyte phagocytosis, in the presence and absence of MSCs. In nonphagocytotic MSC/MG cocultures, slightly elevated levels of TNF- $\alpha$ and PGE2, and highly (by about two magnitude orders) increased levels of IL-10 were measured in comparison to both MG and MSC mono-cultures. In response to 24- and 48-h exposure to yeast cells, monocultured MGs showed a more than 6- and 25-fold increase of TNF- $\alpha$ (Fig. 2A, D) and an about 3- and 5-fold elevation in IL-10 (Fig. 2B, E) production, respectively. As expected, apoptotic thymocytes alone did not evoke measurable changes in either TNF- $\alpha$ or IL-10 production in MG monocultures. In the cocultures, however, they caused a significant increase in the production of IL-10 and PGE2. In MG/ MSC cocultures, yeast loading resulted in a much higher increase in the production of TNF- $\alpha$ and PGE2 (in comparison to yeast-loaded mono-MG cultures), while the high IL-10 generation of MG/MSC cocultures was not further increased by yeast loading. The data indicated that the presence of MSCs can alter the cytokine production of MGs, shifting the TNF- $\alpha / \mathrm{IL}-10$ ratio toward an anti-inflammatory cytokine status. It should be noted that no production of cytokines was observed when MSCs were cultured alone.

Since PGE2 seems to play a key role in MSC-macrophage interaction in several other experimental systems $[12,43]$, we also measured the level of this lipid mediator in the collected supernatants of our cultures. As shown in Fig. 2C and F, PGE2 production was detected in all cultures, especially when MGs were cultured in the presence of MSCs. The highest PGE2 level was found in cocultures containing yeast phagocytosing microglia, although MSCs and MGs alone were also able to produce significant amounts of PGE2. Therefore, these results might indicate some relevance of PGE2 in the MG-MSC interaction.

\section{MSCs modulate the release of cytokines and PGE2 by LPS-stimulated microglia}

Next, we assessed whether MSCs affect the TNF- $\alpha$, IL-10, and PGE2 production of microglia when activated by bacterial endotoxin for $48 \mathrm{~h}$. LPS-stimulated MGs produced significantly higher amounts of TNF- $\alpha$ compared with resting microglia (Fig. 3). A concomitant moderate increase in IL-10 and PGE2 levels was also observed in response to 
A

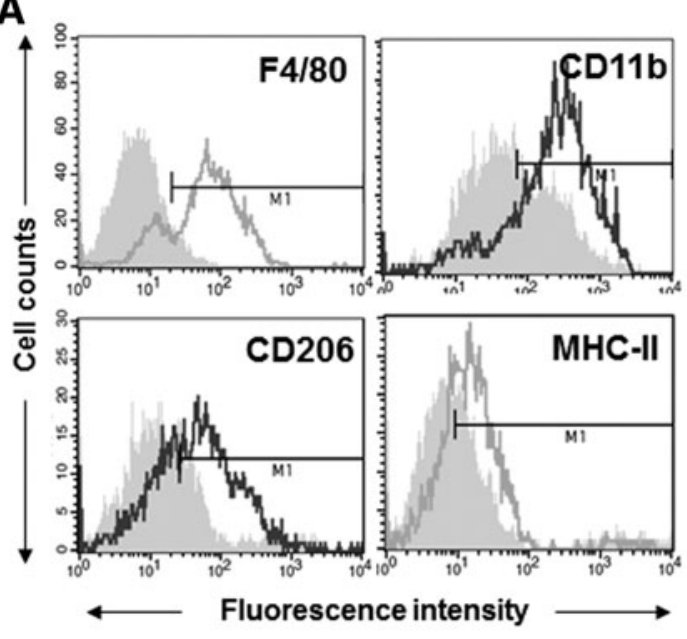

D

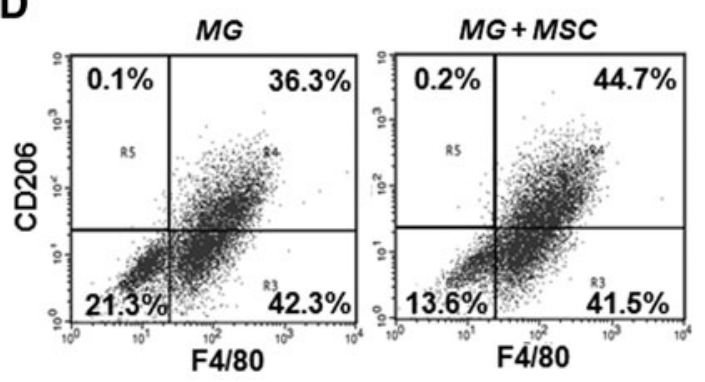

B

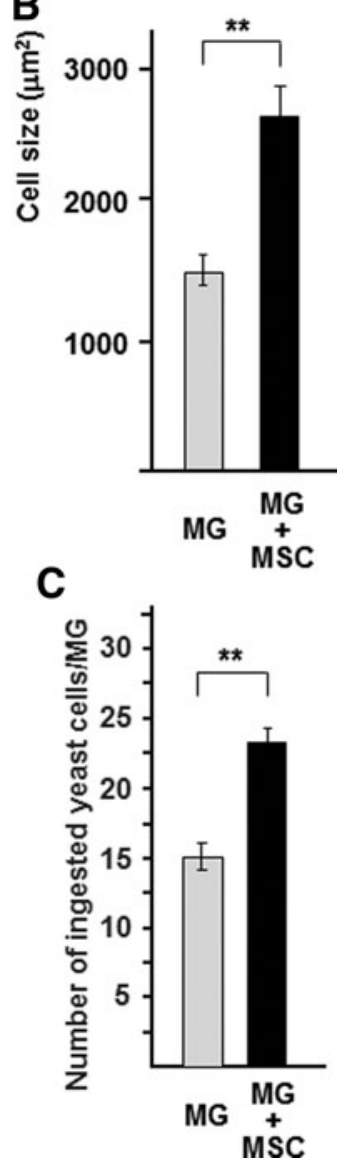

FIG. 1. MSCs induce morphological and functional changes on microglia. (A) Analysis of the phenotype of MGs by flow cytometry. Representative flow cytometry histograms were obtained using individual antibodies (eoloredlines) compared with the corresponding isotype control (shaded in gray). (B) Spreading of microglia. MGs were cultured alone or in the presence of $10^{4}$ bone marrow MSCs for $48 \mathrm{~h}$. The areas of individual cells were measured by appropriate software on images taken by a confocal laserscanning microscope $(n=100, * * P<0.001)$. (C) Changes in the phagocytosis of yeast cells by microglia. $10^{5}$ MGs were cultured with or without $10^{4}$ MSCs for $48 \mathrm{~h}$ and then $5 \times 10^{6}$ yeast cells were added. After $1 \mathrm{~h}$, cultures were fixed and stained with Giemsa solution. The intensity of phagocytosis was quantified by counting ingested yeast particles in individual photographs $(n=100, * * P<0.001)$. (D) Representative dot plots of MGs alone or together with MSCs for F4/80 and CD206 markers by flow cytometry. MGs, microglial cells; MSCs, mesenchymal stem cells.
LPS. Interestingly, neither TNF- $\alpha$ nor IL-10 was detected in the supernatants of LPS-stimulated MSC monocultures (data not shown). When MGs were cocultured with MSCs in the absence of LPS, IL-10 and PGE2 levels significantly increased in the culture media; whereas the production of $\mathrm{TNF}-\alpha$ remained unchanged compared with microglia monocultures. When MGs and MSCs were cocultured in the presence of LPS, the amount of all three mediators increased dramatically. In LPS-treated transwell cultures, the MSCinduced IL-10 and PGE2 increase was significantly reduced, but not completely eliminated; whereas the amount of TNF$\alpha$ was unchanged in comparison to contact cocultures. The data indicated that both soluble mediator(s) and direct cellto-cell contact(s) play crucial roles in MG-MSC interaction.

In order to further clarify the earlier findings, we used a two-step transwell culture system. In the first step, MGs and MSCs were cocultured in the presence or absence of LPS in transwell plates, enabling only humoral cell contacts. After $48 \mathrm{~h}$, the MSC-containing inserts were transferred into new wells without microglia and fresh media was added to all MSC and MG cultures. After an additional incubation for $24 \mathrm{~h}$, the TNF- $\alpha$, IL-10, and PGE2 concentrations were measured in the media by ELISA. As shown in Fig. 4, only MGs secreted significant amounts of TNF- $\alpha$ (Fig. 4A) and IL-10 (Fig. 4B) regardless of the presence or absence of LPS. In contrast, PGE2 was produced by both cell types (MG and MSC) and the production increased in response to LPS stimulation (Fig. 4C). To further validate these results, we measured the $T N F-\alpha$ and $I L-10$ gene expression by
quantitative RT-PCR. In accordance with the ELISA data, no TNF- $\alpha$ or IL-10-specific mRNAs were detected in MSCs, whereas high levels of these messages were observed in MGs (data not shown). Thus, MSCs were unable to produce TNF- $\alpha$ or IL-10 in our experimental system.

Since recent data showed that PGE2 signaling plays an important role in the regulation of IL-10 secretion by phagocytes $[12,43]$, next we compared the kinetics of IL-10 and PGE2 production in MG-MSC cocultures after 4, 24, 48 , and $72 \mathrm{~h}$ of incubation. We observed that levels of PGE2 significantly increased in the coculture medium during the first $24 \mathrm{~h}$ of coculture (MG+MSC), and were further enhanced in response to LPS (MG+MSC+LPS) (Fig. 5B). The presence of MSCs could upregulate the production of IL-10 by MGs in both the presence and absence of LPS (MG and MG+LPS), but only during the second and third days of coculturing (Fig. 5A). The data suggested that PGE2 could be an inductor of microglial IL-10 secretion in MG/ MSC cocultures.

\section{MSCs increase arginase 1 and MCP-1 expression in MGs}

Since arginase $1(\operatorname{Arg} 1)$ is known as a marker of alternatively activated phagocytes, we assessed whether the presence of MSCs could change the microglial expression of the enzyme [44]. As shown in Fig. 6A, the Arg1 mRNA expression was markedly upregulated by MSCs (MG+ MSC) if compared with the levels observed in monocultures of either MGs or MSCs. The presence of MSCs induced a similar (more than threefold) enhancement of the 
FIG. 2. The cytokine production of MGs is different after phagocytosis of yeast or apoptotic thymocytes. $10^{5}$ MGs were incubated for $24 \mathrm{~h}(\mathbf{A}-\mathbf{C})$ or $48 \mathrm{~h}$ (D-F) after phagocytosis of yeast or apoptotic thymocytes in the presence or absence of $10^{4}$ MSCs. After the culturing period, we collected supernatants and measured the amount of TNF- $\alpha(\mathbf{A}, \mathbf{D})$, IL-10 $(\mathbf{B}, \mathbf{E})$, and PGE2 $(\mathbf{C}, \mathbf{F})$ by quantitative ELISA kits according to the manufacturer's instructions. The results are shown as mean $\pm \operatorname{SD}(n=3$, $* P<0.05$ and $* * P<0.001$ compared with MG control). IL, interleukin; PGE2, prostaglandin E2; TNF- $\alpha$, tumor necrosis factoralpha.
A

A

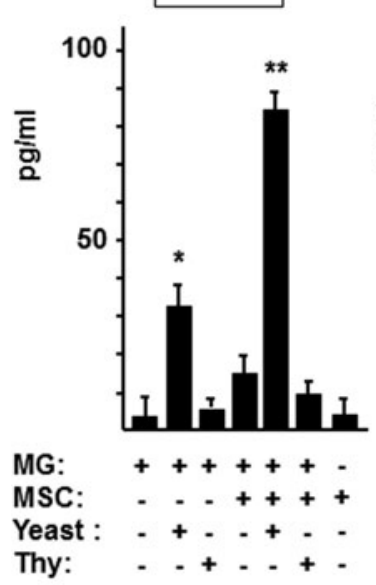

D
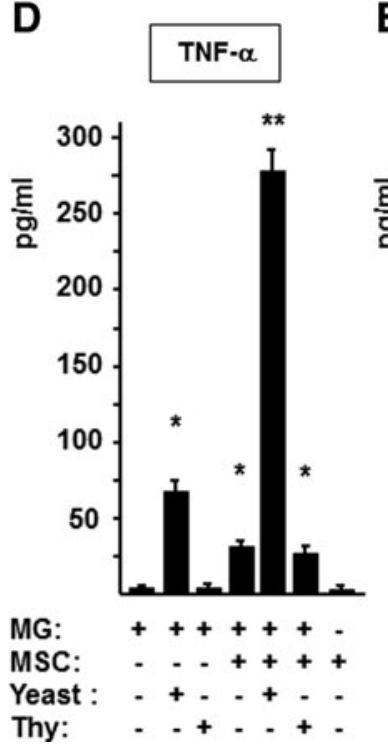

A

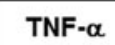

FIG. 3. MSCs modulate the release of cytokines and PGE2 by LPS-stimulated microglia. MGs $\left(10^{5} /\right.$ well $)$ were incubated alone or with MSCs $\left(10^{4} /\right.$ well $)$ in the presence or absence of $10 \mu \mathrm{g} / \mathrm{mL}$ LPS in the indicated combinations for $48 \mathrm{~h}$. In transwell experiments, the two cell types were separated from each other by a $1 \mu \mathrm{m}$ pore-sized semi-permeable membrane. The concentrations of TNF- $\alpha$, IL-10, and PGE2 in the collected supernatants were measured with quantitative ELISAs. The results are shown as mean \pm standard deviation $(n=3, * P<0.05$ and $* * P<0.001$ compared with MG control).

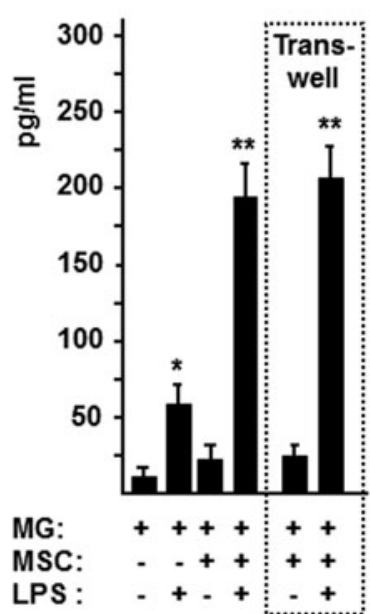

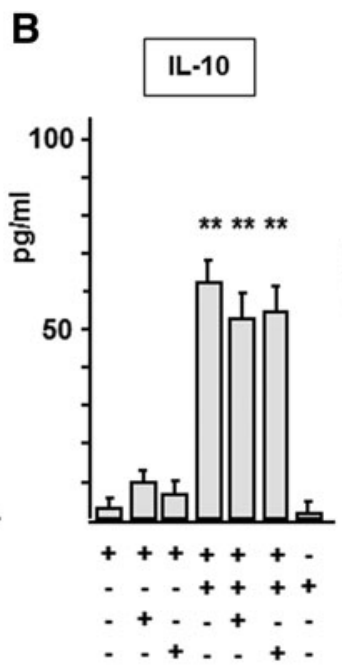
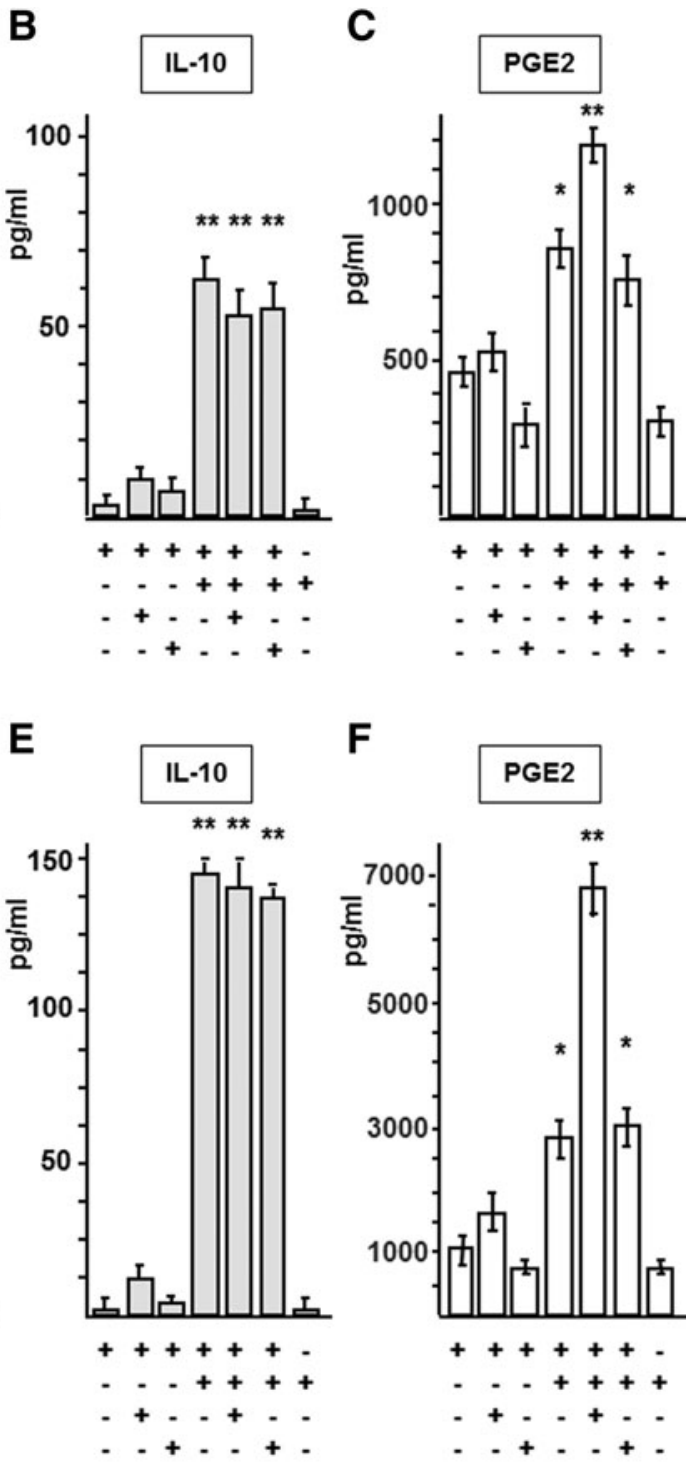

B
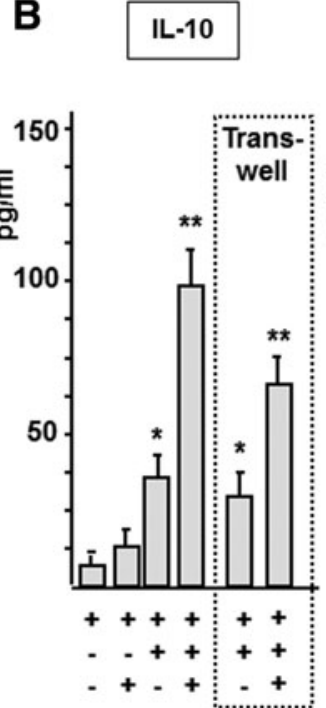

C

PGE2

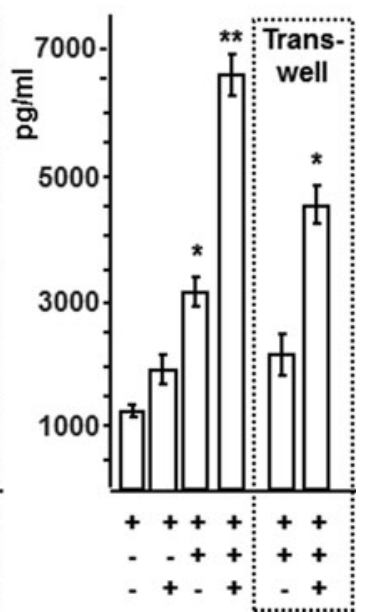


A

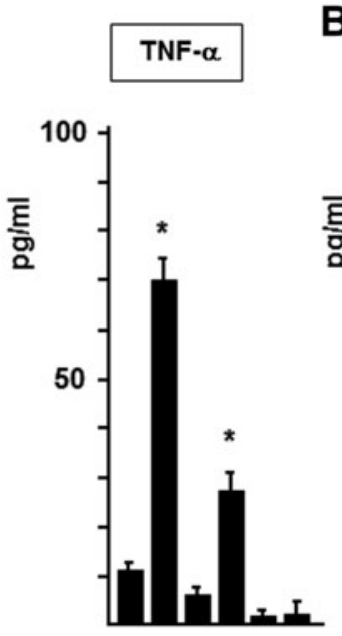

B

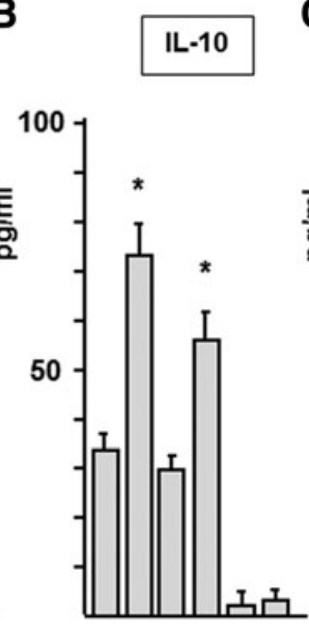

C

PGE2

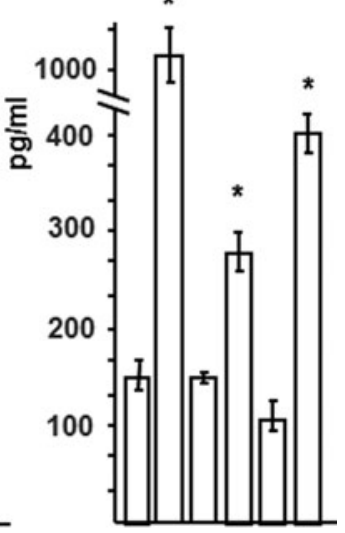

MG + MSC

MG (well):

MSC (insert):

LPS:

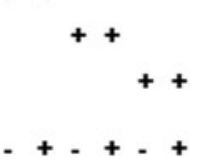

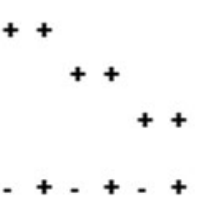

FIG. 4. Cytokines are mainly produced by microglia in the two-step transwell culture system. To clarify the identity of mediator producing cell(s) in the MG-MSC cocultures, MGs $\left(10^{5} /\right.$ well $)$ and MSCs $\left(10^{4} /\right.$ well $)$ were coincubated in the transwell for $48 \mathrm{~h}$ in the presence or absence of $10 \mu \mathrm{g} / \mathrm{mL}$ LPS; then, the culture media was replaced. In half of the samples, the two cell types remained together in the same wells (MG + MSC in trans-well); whereas in the other half of the samples, MSC-containing inserts were transferred to new, empty wells [MSC (insert)] and, thus, separated from the MGs that stayed in the original wells [MG (well)]. After an additional $24 \mathrm{~h}$ of incubation, we collected samples from the supernatants and measured the concentrations of TNF- $\alpha$, IL-10, and PGE2 by ELISA. The results are shown as mean \pm standard deviation form $(n=3$ $* P<0.05$ compared with appropriate control).

MGs was slightly attenuated when the cells were separated in transwell dishes. LPS alone (MG+LPS) could induce only a 1.5 -fold increase in the MCP-1/CCL2 expression in microglia. Similar results were obtained when Arg1 and MCP-1 concentrations were measured in the culture supernatants by quantitative ELISA (Fig. 6C, D).

\section{MSCs exert opposite effects on IL-1 $\beta$ and NALP3 expression of microglia}

Since previous data [35] demonstrated an elevated IL-1 $\beta$ production by LPS-stimulated MGs in the presence of added to the cocultures. The effect of MSCs on LPS-activated

A

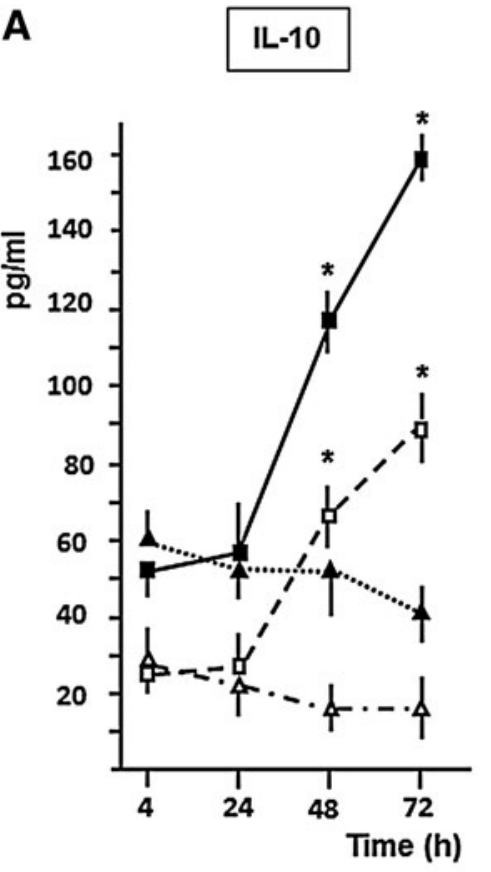

B
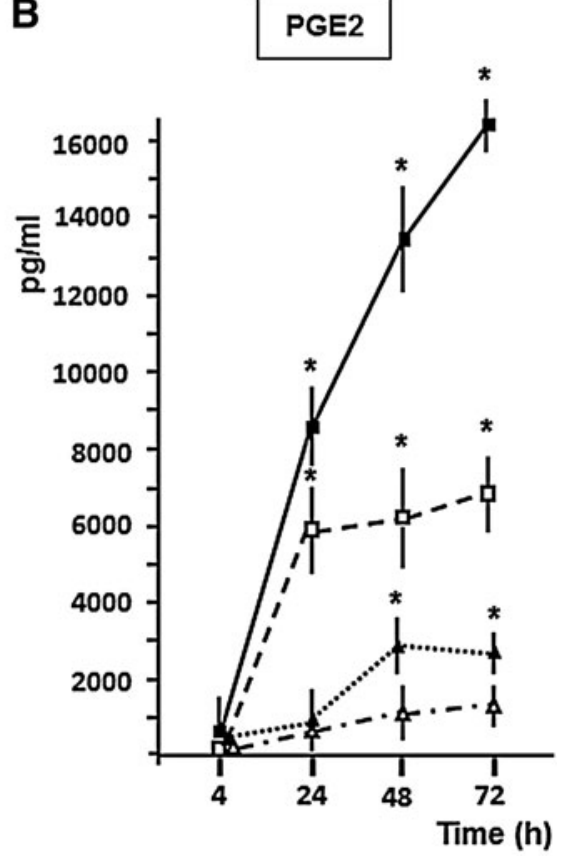

FIG. 5. The time kinetic analysis indicates a connection between PGE2 and IL-10 production. MGs $\left(10^{5} /\right.$ well $)$ were cultured alone or with MSCs $\left(10^{4} /\right.$ well $)$ in the presence or absence of $10 \mu \mathrm{g} / \mathrm{mL}$ LPS in the indicated combinations. Supernatants were collected after the 4th, 24th, 48th and 72nd hours of incubation. The amounts of IL-10 and PGE2 were measured with quantitative ELISAs. Values are expressed as mean \pm SD of three independent experiments $(* P<0.05$ compared with appropriate control). 
FIG. 6. MSCs increase Arg1 and MCP-1 expression in MGs. MGs ( $10^{5} /$ well) were cultured alone or with MSCs $\left(10^{4} /\right.$ well $)$ in the presence or absence of $10 \mu \mathrm{g} / \mathrm{mL}$ LPS in cocultures or in a transwell arrangement for $5 \mathrm{~h}$. RNA samples were isolated using Trizol reagent. After purification and reverse transcription, real-time PCR was performed. The figure shows fold changes in the expression of Arg1 (A) and MCP-1 (B) genes compared with MG control. Results obtained for Arg1 and MCP-1 mRNA expression were also confirmed at protein level by quantitative ELISA after $48 \mathrm{~h}$ of incubation (C, D). The results are shown as mean \pm standard deviation of three independent experiments $(* P<0.05$ and $* * P<0.001)$. Arg1, arginase 1; MCP-1, monocyte chemoattractant protein-1; PCR, polymerase chain reaction.
A

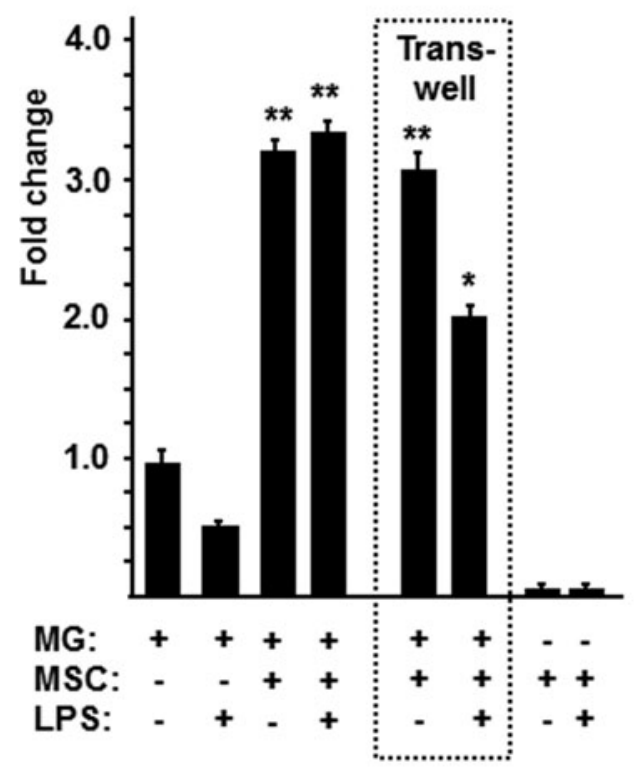

C

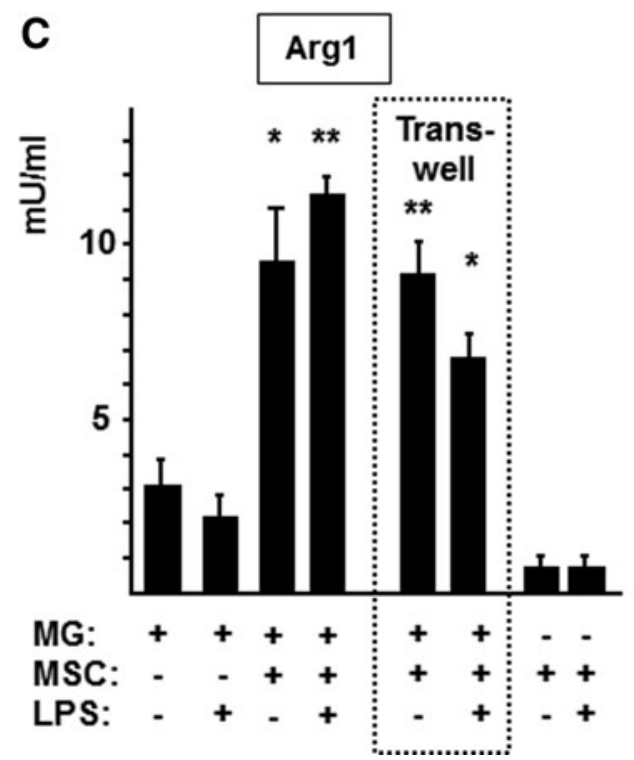

B
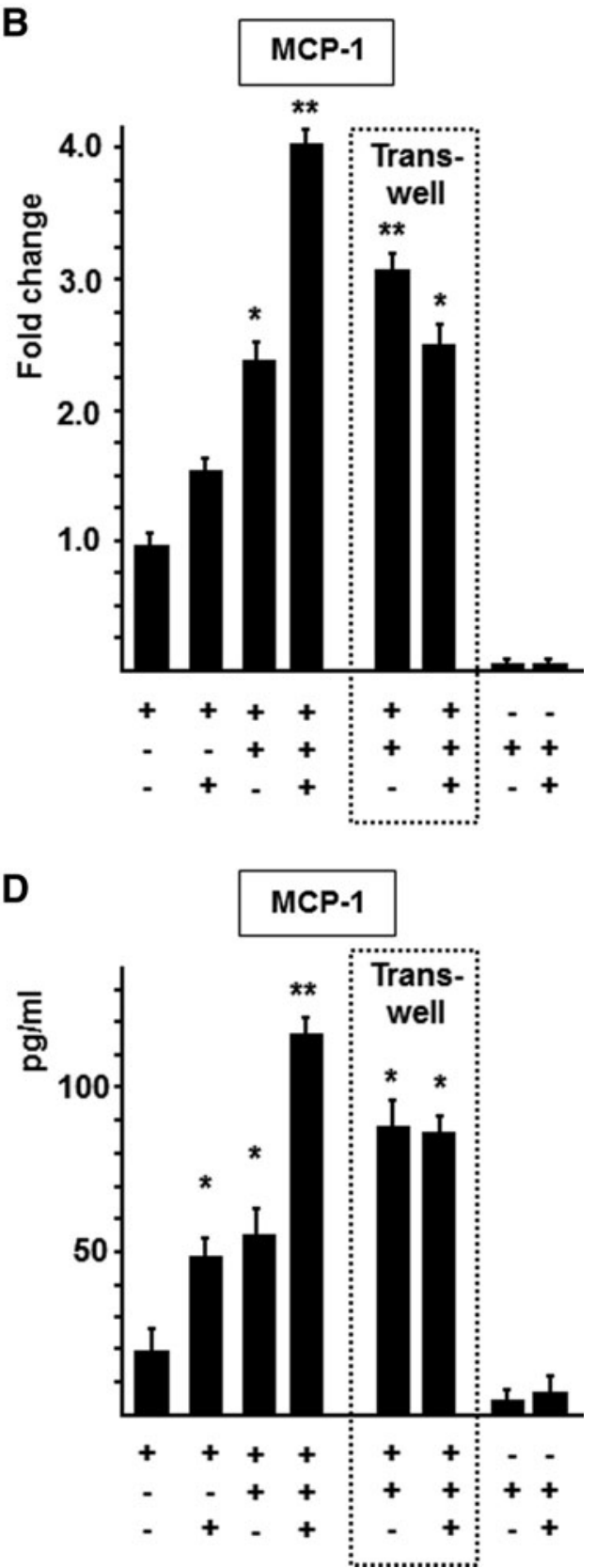

MSCs, we assessed whether MSCs have an impact on the transcription of IL-1 $\beta$ and NALP3 in resting and LPSstimulated microglia. We found that IL-1 $\beta$ mRNA-level in MGs was similarly (seven- to eightfold) enhanced in the presence of LPS or MSCs (Fig. 7A, MG+LPS and MG+ MSC). When MGs and MSCs were cocultured in the presence of LPS, however, the IL- $1 \beta$ expression dramatically increased (by about 40-fold), indicating that the endotoxin and stem/stromal cells act synergistically in activation of microglial IL-1 $\beta$ mRNA expression. In contrast, the level of IL-1 $\beta$ protein in the supernatants was increased by only fourfold under identical conditions (Fig. 7B). LPS also increased the expression of NALP3 mRNA (Fig. 7C, MG+ LPS). In contrast to the synergism in IL- $1 \beta$ regulation, however, the presence of MSCs resulted in a significant downregulation of NLRP3 gene expression in MGs, in both the presence $(\mathrm{MG}+\mathrm{MSC}+\mathrm{LPS})$ and absence $(\mathrm{MG}+\mathrm{MSC})$ of LPS. This effect of MSCs was also confirmed in a transwell system. The data indicated that MSCs exert opposite effects on IL-1 $\beta$ and NALP3 mRNA expression by MGs and that the net IL- $\beta$ protein secretion is a result of these opposite effects.

\section{MSCs enhance the antigen-presenting capacity of MGs toward in vivo preactivated T lymphocytes}

To investigate whether microglial antigen-presenting ability was modulated by MSCs, we analyzed their capacity to induce proliferation of in vivo OVA primed $\mathrm{T}$ lymphocytes in the presence or absence of MSCs. To this end, T cells $\left(95 \% \mathrm{CD}^{+}\right)$were purified from the inguinal and popliteal lymph nodes of mice immunized with a mixture of 

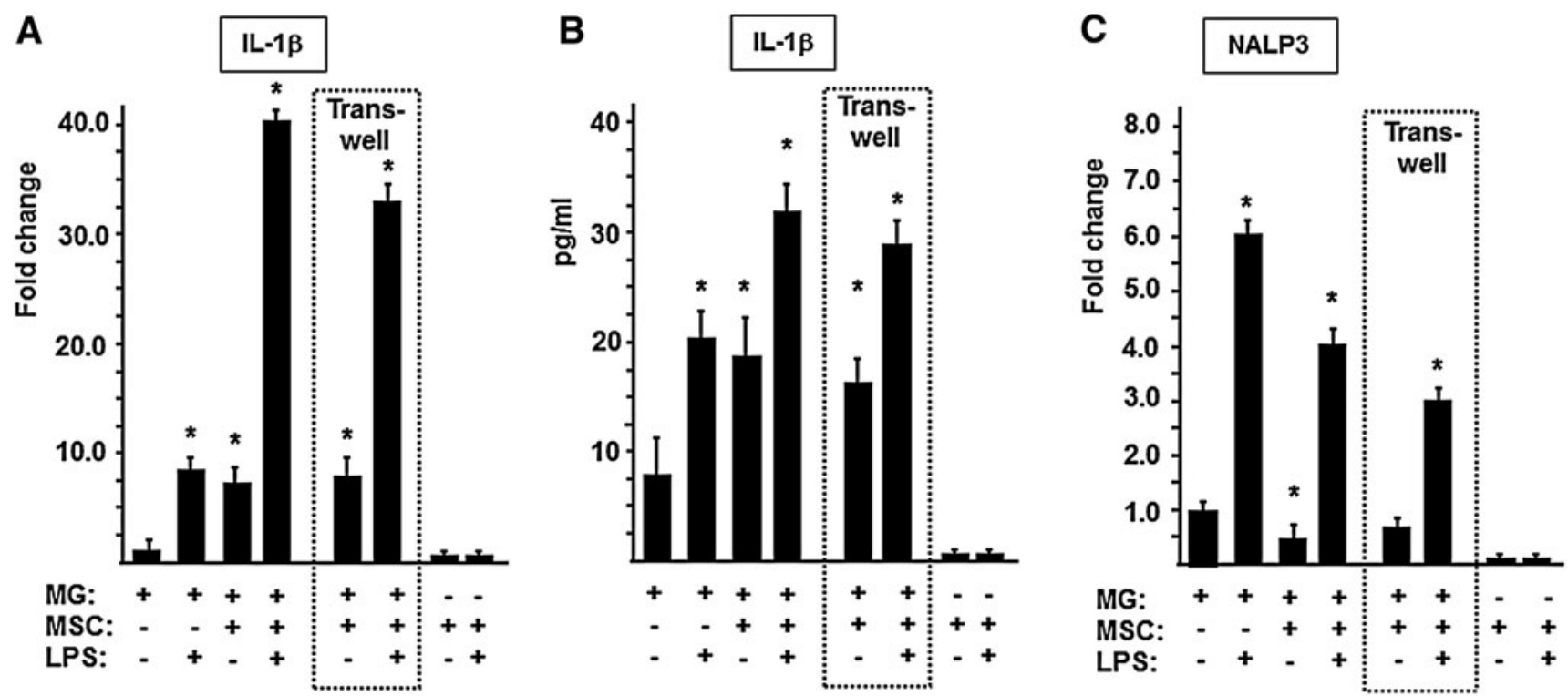

FIG. 7. MSCs have an opposite effect on the expression of IL-1 $\beta$ and NALP3 by microglia. MGs ( $10^{5} /$ well) were cultured alone or with MSCs $\left(10^{4} /\right.$ well) in the presence or absence of $10 \mu \mathrm{g} / \mathrm{mL}$ LPS in cocultures or in a transwell arrangement for $5 \mathrm{~h}$. RNA samples were isolated using Trizol reagent. After purification and reverse transcription, IL-1 $\beta$ (A)- and NALP3 (C)-specific real-time PCR was performed. Supernatants were also collected, and the amount of IL-1 $\beta$ protein was measured with quantitative ELISAs (B). Values are expressed as mean \pm standard deviation of three independent experiments $(* P<0.05$ compared with MG control).

OVA and CFA 7 days earlier, and cocultured with MGs $\left(10^{4}\right.$ cells/well), or MGs and MSCs $\left(10^{3}\right.$ cells/well) in the presence of 4,20 , and $100 \mu \mathrm{g} / \mathrm{mL}$ OVA, respectively. As shown in Fig. 8A, MGs were able to induce antigen-specific T-cell $\left(2 \times 10^{5}\right.$ cells/well $)$ proliferation in a dose-dependent manner when soluble OVA was also present in the cultures. Surprisingly, when MSCs were also added to the system, Tlymphocyte proliferation induced by the OVA-presenting microglia significantly increased (about twofold) compared with the control (T-cell + MG + OVA) cultures. In addition, the percentage of $\mathrm{CD} 4{ }^{+} \mathrm{CD} 25^{\text {high }} \mathrm{Foxp}^{+}$(regulatory) $\mathrm{T}$ cells also slightly but reproducibly increased in the cocultures $(1.15 \pm 0.12$ vs. $1.63 \pm 0.21, P<0.05, n=5$ ) (Supplementary Fig. S3). MSCs alone, however, were unable to induce expansion of OVA-specific T lymphocytes. In contrast, the same MSCs could markedly inhibit mitogen(ConA) and alloantigen-induced (MLR) T-cell proliferation (Fig. 8B, C) at an identical (1:20) MSC: T lymphocyte ratio, as expected. Thus, MSCs seem to be able to enhance the antigen-presenting ability of MGs in cocultures where activated $\mathrm{T}$ cells are present.

To further validate these results, we measured whether MSCs affect the expression of MHC class II antigen and/or CD86 by MGs in coculture. We found that MSCs did not modify significantly MHC class II antigen expression on the surface of MGs (data not shown), whereas the expression of costimulatory CD86 molecules was significantly upregulated. The percentage of $\mathrm{CD} 86^{+} \mathrm{MGs}$, as well as the mean fluorescence intensity, that is, the surface density of CD86 molecules on the microglia were increased in the presence of MSCs $(72.3 \% \pm 4.8 \%$ vs. $94.1 \% \pm 4.3 \%, P<0.05$ and $63.8 \pm 5.1$ vs. $127.5 \pm 6.7, P<0.001, n=3$ ) (Fig. $8 D$ ). In addition, neither MHC class II nor CD86 expression by MSCs was observed under any culture conditions used in this work (data not shown). This suggests that MSCs are able to regulate the antigen-presenting ability of microglia by increasing their costimulatory molecule (CD86) expression.

\section{Discussion}

MGs are specialized tissue macrophages of the CNS that continuously survey their environment with highly motile extensions. In contrast to neurons and macroglial (astro- and oligodendroglia) cells, MGs are of hematopoietic origin and play crucial roles in the defense of CNS tissue integrity. The activated microglia can adopt an "amoeboid" phenotype and produce an enormous array of pro-inflammatory mediators, including cytokines, chemokines, and reactive oxygen species, that contribute to the clearance of pathogens and damaged cells. Prolonged or excessive MG activation, however, could result in pathological forms of inflammation that contribute to the progression of several CNS diseases [46]. In this study, we prepared MGs from the brain of newborn (1-3 days old) mice to investigate their morphology, phenotype, phagocytic activity, pro- and anti-inflammatory mediator production capacity, and antigen-presenting ability in the presence or absence of activating stimuli and then examined how these are regulated by MSCs.

We found that MSCs are able to alter the ratio of IL-10 and TNF- $\alpha$ in favor of the anti-inflammatory cytokine IL-10 in the culture supernatants of MGs on LPS stimulation and under yeast cell or apoptotic thymocyte ingestion. Moreover, the amount of PGE2 changes in a parallel manner with IL-10 in the cocultures. Spatial separation of MGs and MSCs in the transwell slightly ameliorates, but does not eliminate this effect of MSCs. This is consistent with earlier reports indicating that MSCs can shift MGs from an 
A

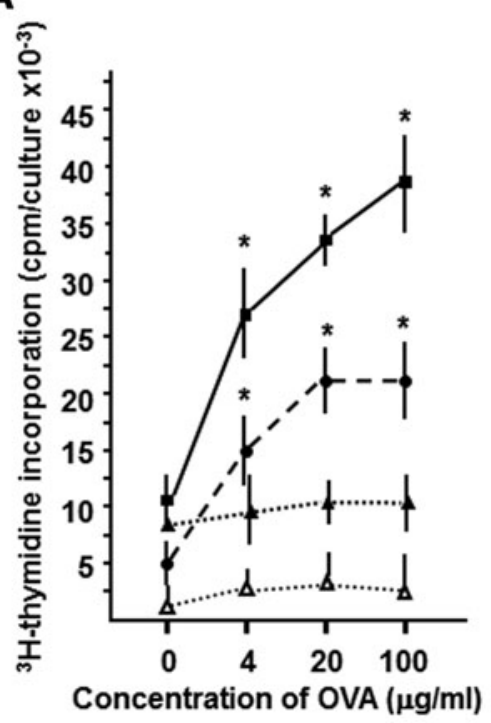

B

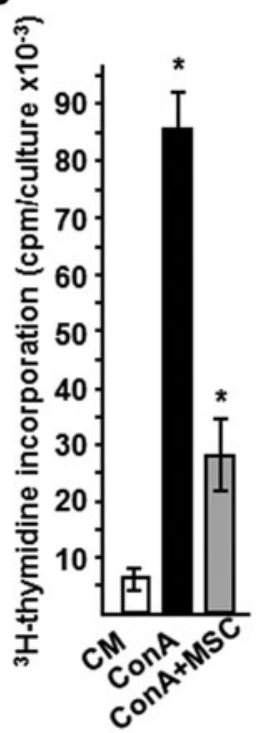

C

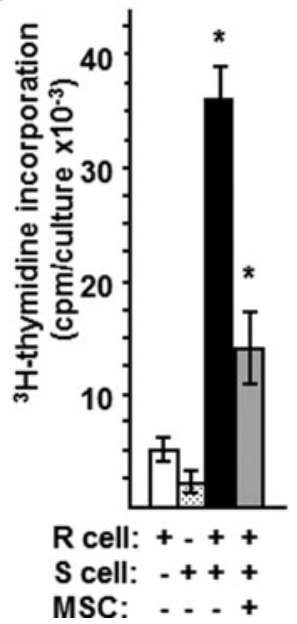

D

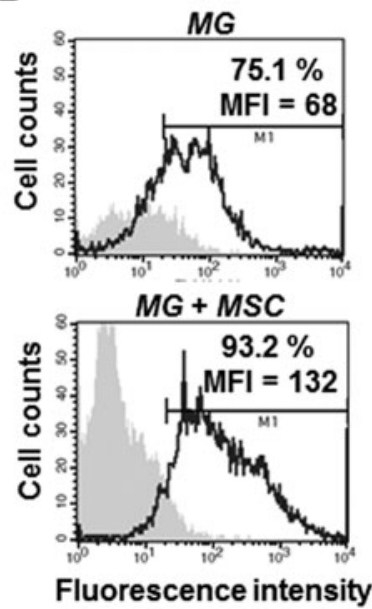

FIG. 8. MSCs enhance the antigen-presenting capacity of MGs. (A) $2 \times 10^{5}$ OVA-specific T cells were added to the cocultures of $10^{4}$ microglia (antigen-presenting cell) and $10^{3}$ MSCs in the presence of various concentrations of OVA in the indicated combinations. After 4 days of culturing, the cells were pulsed with $1 \mu \mathrm{Ci}{ }^{3} \mathrm{H}$-thymidine, incubated for an additional $8 \mathrm{~h}$, and measured for ${ }^{3} \mathrm{H}$-thymidine incorporation. In this figure line, $\triangle \quad \triangle$ represents $\mathrm{T}$ cells alone $\Delta \quad \mathbf{\Delta}$ shows MSC + T-cells, - - $\bullet$ indicates MG + Tcells, while $\longrightarrow$ symbolizes $\mathrm{MG}+\mathrm{MSC}+\mathrm{T}$-cells. The results represented in $\mathrm{cpm}$ are shown in the form of mean \pm SD of triplicate $\left({ }^{*} P<0.05\right.$ compared with control) (B) ${ }^{3} \mathrm{H}$-thymidine incorporation of naive $(\mathrm{CM})$ or mitogen (ConA, $5 \mu \mathrm{g} / \mathrm{mL})$ stimulated $\mathrm{T}$ cells $\left(10^{6} / \mathrm{well}\right)$ in the presence or absence of MSCs $\left(5 \times 10^{4} /\right.$ well $)(n=3, * P<0.05$ compared with control). (C) ${ }^{3} \mathrm{H}$-thymidine incorporation measured in mixed lymphocyte reaction of $2-3 \times 10^{5}$ responder ( $\mathrm{R}$ cell) and $2-3 \times 10^{5}$ irradiated ( $30 \mathrm{~Gy}$ ) stimulator (S cell) splenocytes in the presence or absence of MSCs $\left(5 \times 10^{4} /\right.$ well $)(n=3, * P<0.05$ compared with control $)$. (D) Representative flow cytometry histograms of MGs alone (above) or together with MSCs (below) obtained using APCconjugated monoclonal antibodies against CD86 (black lines) compared with the corresponding isotype control (shaded in gray). CM, complete medium; ConA, concanavalin A; CPM, counts per minute; OVA, ovalbumin.

inflammatory (M1-like) into an anti-inflammatory (M2like) phenotype $[26,31,36]$ mainly through $\mathrm{COX}-2$ mediated production of PGE2 and possibly some other soluble factors $[35,37]$. Similar PGE2-mediated interaction was also described between other tissue macrophages and MSCs in vitro [12], as well as in vivo [43]. In addition, the MSCinduced shift in microglia polarization was further affirmed by the fact that MGs express a high amount of Arg1, another molecule typical for M2-like phagocytes, regardless of the presence or absence of LPS in the cocultures. It is noteworthy that our findings differ from those reported by Tseng et al. [38], because in their work MSCs did not affect the expression of Arg1 by microglia. The discrepancy between studies by Tseng et al. [38] and those in our work could be explained by differences in the source of MGs (rat vs. mouse) and the concentration of LPS (100 ng/mL vs. $10 \mu \mathrm{g} / \mathrm{mL})$ used in the cocultures.

More importantly, we could clearly see that MSCs themselves are able to induce some kind of microglia activation without any further stimuli. MGs had a larger-sized ("amoeboid" phenotype), increased phagocytic activity, and mannose receptor (CD206) expression in the presence of MSCs compared with MGs cultured alone. This is consistent with the study by Kim and Hematti [26] showing that human MSCs can increase the phagocytic activity and the expression of CD206 molecules by monocyte-derived macrophages. MSC-stimulated phagocytosis of apoptotic cells and zymosan particles by other tissue macrophages was also observed by Maggini et al. [12] and Zhang et al. [27], respectively. Moreover, we also found a significant amount of soluble mediators, especially IL-10 and PGE2, in the supernatants of MGs cocultured with MSCs. Concomitantly, a low level of TNF- $\alpha$ production was also observed. These data, along with the MSC-induced expression of Arg1 enzyme by microglia (see above), indicate that stem/stromal cells are indeed able to induce an MG phenotype with several characteristics of alternatively activated (M2) phagocytes without any additional pro-inflammatory stimuli. The real picture, however, is much more complicated. A relatively high amount of two pro-inflammatory mediators, MCP-1/CCL2 and IL-1 $\beta$, are also expressed by MGs on MSC coculture. We can only speculate that due to the fact that mononuclear phagocytes with various phenotypic polarization are crucial for tissue repair and regeneration $[47,48]$, the MCP-1/CCL2-induced microglia accumulation at the site of tissue injury or inflammation could have a beneficial effect on the repair process. On the other hand, the IL- $1 \beta$ secretion by MGs in the presence of stem cells is consistent with an earlier report [35] and could be explained by two facts. First, IL-1 $\beta$, as a powerful proinflammatory cytokine, is involved in the "licensing" of MSCs necessary to exert their immunosuppressive properties [7]. Second, based on a recent report, it could also be a growth factor for stromal cells in vitro as well as in vivo [49]. Interestingly, however, MSCs have an opposite effect on the expression of NALP3 that are specific mRNAs in MGs, especially when LPS is also present in the cocultures. Thus, the net amount of active IL- $1 \beta$ protein secreted by microglia is always limited in the presence of MSCs. The reason to keep the expression level of NALP3 relatively low in MGs is not yet clear but might be explained by the cytokine-independent effects of the inflammasome under 
conditions of cellular stress. Too high an NALP3 level could be dangerous for microglia by inducing pyroptosis, a caspase-1-dependent form of programmed cell death [50]. In line with this, Licandro et al. [51] recently suggested that NALP3 modulates a number of signal pathways involved in DNA damage response and apoptosis.

Finally, the most intriguing aspect of this study is the enhanced proliferation of in vivo primed, antigen-specific $\mathrm{T}$ lymphocytes in MG-MSC cocultures, that is, the increased antigen-presenting ability of microglia on MSC coculture. Notably, MSCs are able to increase the expression of costimulatory molecule CD86, but not MHC class II antigens by MGs in our experimental settings. This property of MSCs is surprising, because several earlier reports indicated their opposite effect on the antigen-presenting ability of dendritic cells [52,53]. Moreover, when thyoglicolate-elicited mouse peritoneal macrophages were cocultured with MSCs in the presence of LPS, impaired antigen presentation and reduced surface expression of MHC class II, CD80, and CD86 molecules were observed [12]. Maggini et al. [12], however, measured primary $\mathrm{T}$-cell response using $\mathrm{CD} 4^{+}$splenocytes derived from an OVA-specific T-cell receptor transgenic (OT-II) mouse. GM-CSF-treated human monocytes also showed reduced CD40, CD80, and CD86 expression, but increased MHC class II expression in the presence of MSCs [54]. By contrast, a previous work has demonstrated that MSCs do not inhibit T-cell proliferation when they are added to recall antigen-stimulated human peripheral blood mononuclear cells in vitro [55]. In addition, mouse MSCs are able to augment naive $\mathrm{CD} 4^{+}$, as well as $\mathrm{CD} 8^{+}{ }^{-}$-cell proliferation through the MCP-1/CCL2-CCL2 receptor pathway when a low MSC:T-cell ratio (1:10) is used in the cultures [56]. Moreover, apart from the effects on antigenpresenting ability and CD86 expression of microglia, MSCs also slightly increased the ratio of $\mathrm{CD} 4{ }^{+} \mathrm{CD} 25^{\text {high }} \mathrm{Foxp}^{+}$ (regulatory) T-cells in the cocultures, another well-established function of these stem/stromal cells in vitro [57,58] as well as in vivo [59]. Therefore, we suggest that these conflicting results might be explained by differences regarding cell types (microglia vs. peritoneal macrophage; naïve vs. antigen-experienced T cell), cell source (mouse vs. human), and the presence or absence of additional pro-inflammatory stimuli (eg, LPS) in the cocultures.

In conclusion, we found that MSCs induce a mixed microglia phenotype defined as Arg1-high, CD86-high, CD206-high, IL-10-high, PGE2-high, MCP-1/CCL2-high, IL-1 $\beta$-moderate, NALP-3-low, and TNF- $\alpha$-low cells. These MSC-elicited MGs have high phagocytic activity and antigen-presenting ability. LPS is able to shape this MG phenotype quantitatively, but not qualitatively in the presence of MSCs. This unique polarization state resembles a novel regulatory microglia phenotype, which might contribute to the resolution of inflammation and to tissue repair in the CNS.

\section{Acknowledgments}

The authors thank László Barna, the Nikon Microscopy Center at IEM, Nikon Austria GmbH, and Auro-Science Consulting Ltd. for kindly providing microscopy support. This work received financial support from the program No. KTIA_AIK_12-1-2012-0025 (Hungary).

\section{Author Disclosure Statement}

The authors have no conflicting financial interests.

\section{References}

1. Friedenstein A, R Chailakhjan and K Lalykina. (1970). The development of fibroblast colonies in monolayer cultures of guinea-pig bone marrow and spleen cells. Cell Tissue Kinet 3:393-403.

2. da Silva Meirelles L, PC Chagastelles and NB Nardi. (2006). Mesenchymal stem cells reside in virtually all postnatal organs and tissues. J Cell Sci 119:2204-2213.

3. da Silva Meirelles L, AI Caplan and NB Nardi. (2008). In search of the in vivo identity of mesenchymal stem cells. Stem Cells 26:2287-2299.

4. Beltrami AP, D Cesselli, N Bergamin, P Marcon, S Rigo, E Puppato, F D'Aurizio, R Verardo, S Piazza, et al. (2007). Multipotent cells can be generated in vitro from several adult human organs (heart, liver, and bone marrow). Blood 110:3438-3446.

5. Uccelli A, L Moretta and V Pistoia. (2008). Mesenchymal stem cells in health and disease. Nat Rev Immunol 8: 726-736.

6. Dimarino AM, AI Caplan and TL Bonfield. (2013). Mesenchymal stem cells in tissue repair. Front Immunol 4:201.

7. Bernardo ME and WE Fibbe. (2013). Mesenchymal stromal cells: sensors and switchers of inflammation. Cell Stem Cell 13:392-402.

8. Di Nicola M, C Carlo-Stella, M Magni, M Milanesi, PD Longoni, P Matteucci, S Grisanti and AM Gianni. (2002). Human bone marrow stromal cells suppress T-lymphocyte proliferation induced by cellular or nonspecific mitogenic stimuli. Blood 99:3838-3843.

9. Le Blanc K, L Tammik, B Sundberg, SE Haynesworth and O Ringdén. (2003). Mesenchymal stem cells inhibit and stimulate mixed lymphocyte cultures and mitogenic responses independently of the major histocompatibility complex. Scand J Immunol 57:11-20.

10. Corcione A, F Benvenuto, E Ferretti, D Giunti, V Cappiello, F Cazzanti, M Risso, F Gualandi, GL Mancardi, V Pistoia and A Uccelli. (2006). Human mesenchymal stem cells modulate B-cell functions. Blood 107:367-372.

11. Spaggiari GM, A Capobianco, S Becchetti, MC Mingari and L Moretta. (2006). Mesenchymal stem cell-natural killer cell interactions: evidence that activated NK cells are capable of killing MSCs, whereas MSCs can inhibit IL-2-induced NK-cell proliferation. Blood 107:14841490 .

12. Maggini J, G Mirkin, I Bognanni, J Holmberg, IM Piazzón, I Nepomnaschy, H Costa, C Cañones, S Raiden, M Vermeulen and JR Geffner. (2010). Mouse bone marrow-derived mesenchymal stromal cells turn activated macrophages into a regulatory-like profile. PLoS One 5:e9252.

13. Yañez R, A Oviedo, M Aldea, JA Bueren and ML Lamana. (2010). Prostaglandin E2 plays a key role in the immunosuppressive properties of adipose and bone marrow tissuederived mesenchymal stromal cells. Exp Cell Res 316: 3109-3123.

14. Chen K, D Wang, W Du, Z Han, H Ren, Y Chi, S Yang, D Zhu, F Bayard and Z Han. (2010). Human umbilical cord mesenchymal stem cells hUC-MSCs exert immunosuppressive activities through a PGE(2)-dependent mechanism. Clin Immunol 135:448-458. 
15. Meisel R, A Zibert, M Laryea, U Göbel, W Däubener and D Dilloo. (2004). Human bone marrow stromal cells inhibit allogeneic T-cell responses by indoleamine 2,3dioxygenase-mediated tryptophan degradation. Blood 103: 4619-4621.

16. Jones BJ, G Brooke, $\mathrm{K}$ Atkinson and SJ McTaggart. (2007). Immunosuppression by placental indoleamine 2,3dioxygenase: a role for mesenchymal stem cells. Placenta 28:1174-1181.

17. Sato K, K Ozaki, I Oh, A Meguro, K Hatanaka, T Nagai, K Muroi and K Ozawa. (2007). Nitric oxide plays a critical role in suppression of T-cell proliferation by mesenchymal stem cells. Blood 109:228-234.

18. Ren G, L Zhang, X Zhao, G Xu, Y Zhang, AI Roberts, RC Zhao and Y Shi. (2008). Mesenchymal stem cell-mediated immunosuppression occurs via concerted action of chemokines and nitric oxide. Cell Stem Cell 2:141-150.

19. Beyth S, Z Borovsky, D Mevorach, M Liebergall, Z Gazit, $\mathrm{H}$ Aslan, E Galun and J Rachmilewitz. (2005). Human mesenchymal stem cells alter antigen-presenting cell maturation and induce T-cell unresponsiveness. Blood 105: 2214-2219.

20. Sheng H, Y Wang, Y Jin, Q Zhang, Y Zhang, L Wang, B Shen, S Yin, W Liu, L Cui and N Li. (2008). A critical role of IFN $\gamma$ in priming MSC-mediated suppression of T cell proliferation through up-regulation of B7-H1. Cell Res 18: 846-857.

21. Xue Q, XY Luan, YZ Gu, HY Wu, GB Zhang, GH Yu, HT Zhu, M Wang, W Dong, YJ Geng and XG Zhang. (2010). The negative co-signaling molecule b7-h4 is expressed by human bone marrow-derived mesenchymal stem cells and mediates its T-cell modulatory activity. Stem Cells Dev 19:27-38.

22. Shi D, L Liao, B Zhang, R Liu, X Dou, J Li, X Zhu, L Yu, $\mathrm{D}$ Chen and RC Zhao. (2011). Human adipose tissuederived mesenchymal stem cells facilitate the immunosuppressive effect of cyclosporin $\mathrm{A}$ on $\mathrm{T}$ lymphocytes through Jagged-1-mediated inhibition of NF- $\mathrm{KB}$ signaling. Exp Hematol 39:214-224.e1.

23. Gieseke F, J Böhringer, R Bussolari, M Dominici, R Handgretinger and I Müller. (2010). Human multipotent mesenchymal stromal cells use galectin-1 to inhibit immune effector cells. Blood 116:3770-3779.

24. Krampera M, L Cosmi, R Angeli, A Pasini, F Liotta, A Andreini, V Santarlasci, B Mazzinghi, G Pizzolo, et al. (2006). Role for interferon-gamma in the immunomodulatory activity of human bone marrow mesenchymal stem cells. Stem Cells 24:386-398.

25. Ryan JM, F Barry, JM Murphy and BP Mahon. (2007). Interferon-gamma does not break, but promotes the immunosuppressive capacity of adult human mesenchymal stem cells. Clin Exp Immunol 149:353-363.

26. Kim YJ, HJ Park, G Lee, OY Bang, YH Ahn, E Joe, HO Kim and PH Lee. (2009). Neuroprotective effects of human mesenchymal stem cells on dopaminergic neurons through anti-inflammatory action. Glia 57:13-23.

27. Zhang QZ, WR Su, SH Shi, P Wilder-Smith, AP Xiang, A Wong, AL Nguyen, CW Kwon and AD Le. (2010). Human gingiva-derived mesenchymal stem cells elicit polarization of $\mathrm{m} 2$ macrophages and enhance cutaneous wound healing. Stem Cells 28:1856-1868.

28. Mosser DM and JP Edwards. (2008). Exploring the full spectrum of macrophage activation. Nat Rev Immunol 8: 958-969.
29. Nimmerjahn A, F Kirchhoff and F Helmchen. (2005). Resting microglial cells are highly dynamic surveillants of brain parenchyma in vivo. Science 308:1314-1318.

30. Davalos D, J Grutzendler, G Yang, JV Kim, Y Zuo, S Jung, DR Littman, ML Dustin and WB Gan. (2005). ATP mediates rapid microglial response to local brain injury in vivo. Nat Neurosci 8:752-758.

31. Zhou C, C Zhang, S Chi, Y Xu, J Teng, H Wang, Y Song and R Zhao. (2009). Effects of human marrow stromal cells on activation of microglial cells and production of inflammatory factors induced by lipopolysaccharide. Brain Res 1269:23-30.

32. Zhou C, C Zhang, R Zhao, S Chi and P Ge. (2013). Human marrow stromal cells reduce microglial activation to protect motor neurons in a transgenic mouse model of amyotrophic lateral sclerosis. J Neuroinflammation 10:52.

33. Kemp K, E Gray, E Mallam, N Scolding and A Wilkins. (2010). Inflammatory cytokine induced regulation of superoxide dismutase 3 expression by human mesenchymal stem cells. Stem Cell Rev 6:548-559.

34. Ooi YY, R Ramasamy, Z Rahmat, H Subramaiam, SW Tan, M Abdullah, DA Israf and S Vidyadaran. (2010). Bone marrow-derived mesenchymal stem cells modulate BV2 microglia responses to lipopolysaccharide. Int Immunopharmacol 10:1532-1540.

35. Giunti D, B Parodi, C Usai, L Vergani, S Casazza, S Bruzzone, G Mancardi and A Uccelli. (2012). Mesenchymal stem cells shape microglia effector functions through the release of CX3CL1. Stem Cells 30:2044-2053.

36. Rahmat Z, S Jose, R Ramasamy and S Vidyadaran. (2013). Reciprocal interactions of mouse bone marrow-derived mesenchymal stem cells and BV2 microglia after lipopolysaccharide stimulation. Stem Cell Res Ther 4:12.

37. Foraker JE, JY Oh, JH Ylostalo, RH Lee, J Watanabe and DJ Prockop. (2011). Cross-talk between human mesenchymal stem/progenitor cells (MSCs) and rat hippocampal slices in LPS-stimulated cocultures: the MSCs are activated to secrete prostaglandin E2. J Neurochem 119:1052-1063.

38. Tseng FW, MJ Tsai, LY Yu, YS Fu, WC Huang and $\mathrm{H}$ Cheng. (2013). Comparative effects of bone marrow mesenchymal stem cells on lipopolysaccharide-induced microglial activation. Oxid Med Cell Longev 2013:234179.

39. Jung S, J Aliberti, P Graemmel, MJ Sunshine, GW Kreutzberg, A Sher and DR Littman. (2000). Analysis of fractalkine receptor CX(3)CR1 function by targeted deletion and green fluorescent protein reporter gene insertion. Mol Cell Biol 20:4106-4114.

40. Hegyi B, B Sági, J Kovács, J Kiss, VS Urbán, G Mészáros, E Monostori and F Uher. (2010). Identical, similar or different? Learning about immunomodulatory function of mesenchymal stem cells isolated from various mouse tissues: bone marrow, spleen, thymus and aorta wall. Int Immunol 22:551-559.

41. Saura J, JM Tusell and J Serratosa. (2003). High-yield isolation of murine microglia by mild trypsinization. Glia 44:183-189.

42. Sági B, P Maraghechi, VS Urbán, B Hegyi, A Szigeti, R Fajka-Boja, G Kudlik, K Német, E Monostori, E Gócza and F Uher. (2012). Positional identity of murine mesenchymal stem cells resident in different organs is determined in the postsegmentation mesoderm. Stem Cells Dev 21:814-828.

43. Németh K, A Leelahavanichkul, P Yuen, B Mayer, A Parmelee, K Doi, P Robey, K Leelahavanichkul, B Koller, et al. (2009). Bone marrow stromal cells attenuate sepsis 
via prostaglandin $\mathrm{E}(2)$-dependent reprogramming of host macrophages to increase their interleukin-10 production. Nat Med 15:42-49.

44. Gordon S. (2003). Alternative activation of macrophages. Nat Rev Immunol 3:23-35.

45. Valente AJ, MM Rozek, EA Sprague and CJ Schwartz. (1992). Mechanisms in intimal monocyte-macrophage recruitment. A special role for monocyte chemotactic protein-1. Circulation 86:III20-5.

46. Saijo K and CK Glass. (2011). Microglial cell origin and phenotypes in health and disease. Nat Rev Immunol 11: 775-787.

47. Murray PJ and TA Wynn. (2011). Protective and pathogenic functions of macrophage subsets. Nat Rev Immunol 11:723-737.

48. Ben-Mordechai T, R Holbova, N Landa-Rouben, T HarelAdar, MS Feinberg, I Abd Elrahman, G Blum, FH Epstein, Z Silman, S Cohen and J Leor. (2013). Macrophage subpopulations are essential for infarct repair with and without stem cell therapy. J Am Coll Cardiol 62:1890-1901.

49. Bigildeev AE, OA Zhironkina, ON Lubkova and NJ Drize. (2013). Interleukin-1 beta is an irradiation-induced stromal growth factor. Cytokine 64:131-137.

50. Strowig T, J Henao-Mejia, E Elinav and R Flavell. (2012). Inflammasomes in health and disease. Nature 481:278-286.

51. Licandro G, H Ling Khor, O Beretta, J Lai, H Derks, F Laudisi, C Conforti-Andreoni, H Liang Qian, GG Teng, P Ricciardi-Castagnoli and A Mortellaro. (2013). The NLRP3 inflammasome affects DNA damage responses after oxidative and genotoxic stress in dendritic cells. Eur J Immunol 43:2126-2137.

52. Liu WH, JJ Liu, J Wu, LL Zhang, F Liu, L Yin, MM Zhang and B Yu. (2013). Novel mechanism of inhibition of dendritic cells maturation by mesenchymal stem cells via interleukin-10 and the JAK1/STAT3 signaling pathway. PLoS One 8:e55487.

53. Cheng P, Y Nefedova, CA Corzo and DI Gabrilovich. (2007). Regulation of dendritic-cell differentiation by bone marrow stroma via different Notch ligands. Blood 109:507-515.

54. Abumaree MH, MA Al Jumah, B Kalionis, D Jawdat, A Al Khaldi, FM Abomaray, AS Fatani, LW Chamley and BA Knawy. (2013). Human placental mesenchymal stem cells (pMSCs) play a role as immune suppressive cells by shifting macrophage differentiation from inflammatory M1 to anti-inflammatory M2 macrophages. Stem Cell Rev 9:620-641.

55. Potian JA, H Aviv, NM Ponzio, JS Harrison and P Rameshwar. (2003). Veto-like activity of mesenchymal stem cells: functional discrimination between cellular responses to alloantigens and recall antigens. J Immunol 171:34263434.

56. Zhou Y, A Day, S Haykal, A Keating and TK Waddell. (2013). Mesenchymal stromal cells augment CD4 + and CD8 + T-cell proliferation through a CCL2 pathway. Cytotherapy 15:1195-1207.

57. Prevosto C, M Zancolli, P Canevali, MR Zocchi and A Poggi. (2007). Generation of CD4 + or CD8 + regulatory T cells upon mesenchymal stem cell-lymphocyte interaction. Haematologica 92:881-888.

58. Maccario R, M Podestà, A Moretta, A Cometa, P Comoli, D Montagna, L Daudt, A Ibatici, G Piaggio, et al. (2005). Interaction of human mesenchymal stem cells with cells involved in alloantigen-specific immune response favors the differentiation of CD4 + T-cell subsets expressing a regulatory/suppressive phenotype. Haematologica 90:516525 .

59. Casiraghi F, N Azzollini, P Cassis, B Imberti, M Morigi, D Cugini, RA Cavinato, M Todeschini, S Solini, et al. (2008). Pretransplant infusion of mesenchymal stem cells prolongs the survival of a semiallogeneic heart transplant through the generation of regulatory T cells. J Immunol 181:39333946.

Address correspondence to: Ferenc Uher, PhD

National Blood Service

Stem Cell Biology Unit

Budapest, Diószegi út 64

Hungary 1113

E-mail: uher.ferenc@gmail.com

Received for publication February 12, 2014

Accepted after revision May 28, 2014

Prepublished on Liebert Instant Online XXXX XX, XXXX 


\section{Supplementary Data}

A

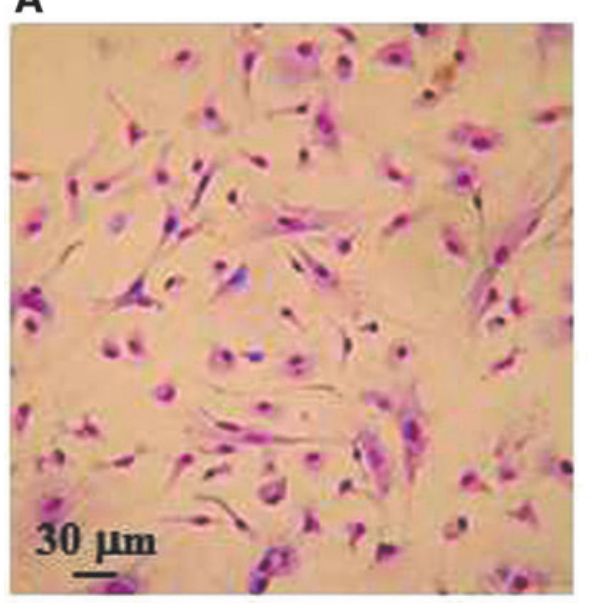

c

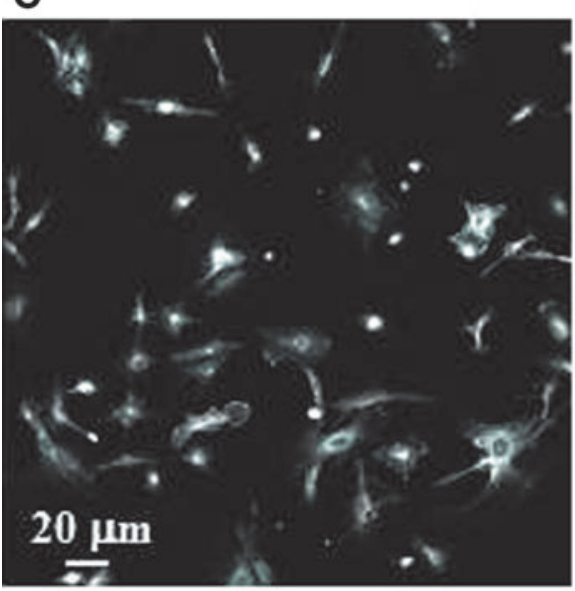

E

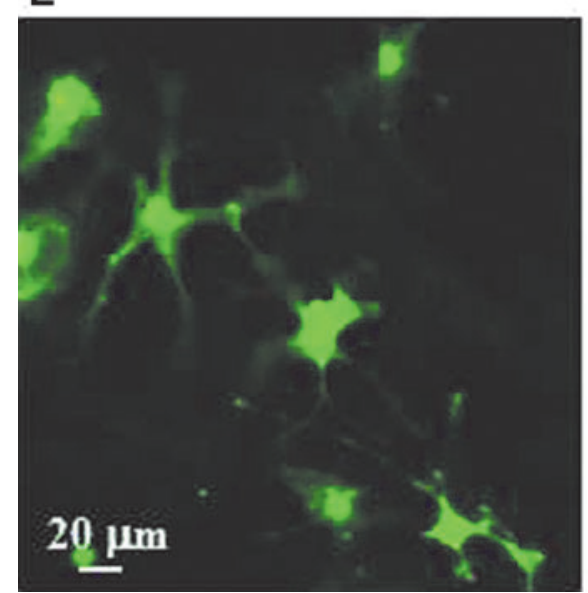

B

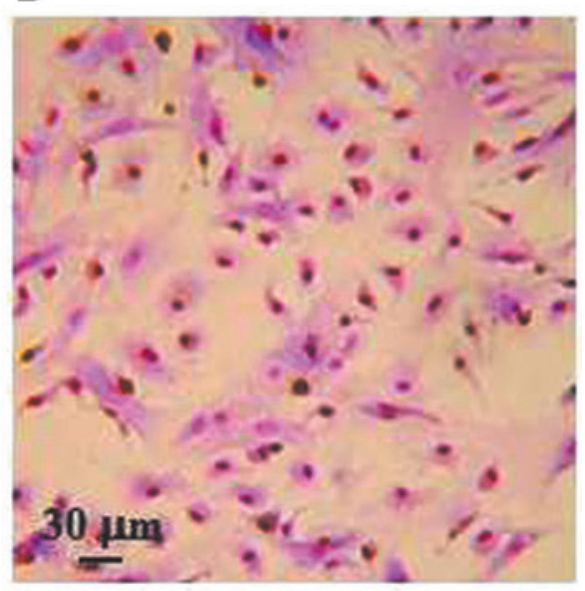

D

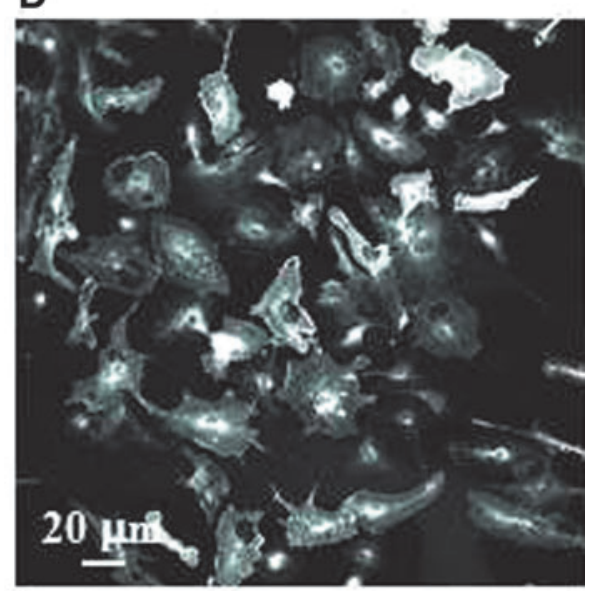

$\mathbf{F}$

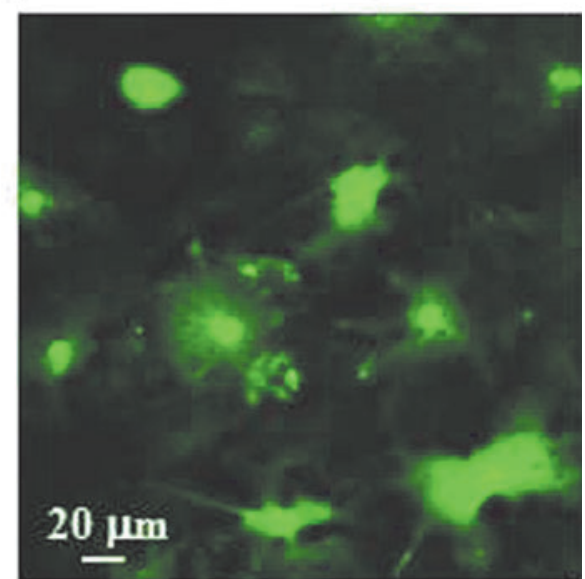

SUPPLEMENTARY FIG. S1. Changes in the morphology and spreading of MGs in the presence of MSCs. $10^{5}$ MGs derived from CD1 mice were incubated alone $(\mathbf{A}, \mathbf{C})$ or in the presence of $10^{4} \mathrm{BM}$ MSCs $(\mathbf{B}, \mathbf{D})$ for $48 \mathrm{~h}$, then fixed with paraformaldehyde, and stained with Giemsa solution $(\mathbf{A}, \mathbf{B})$ or isolectin $\mathrm{B}_{4}(\mathbf{C}, \mathbf{D})$. For fluorescent images, CX3CR1 $1^{+/ G F P}$ MGs were cultured alone (E) or in the presence of $10^{4}$ BM MSCs (F) for 48 h. BM, bone marrow; MGs, microglial cells; MSCs, mesenchymal stem cells. 

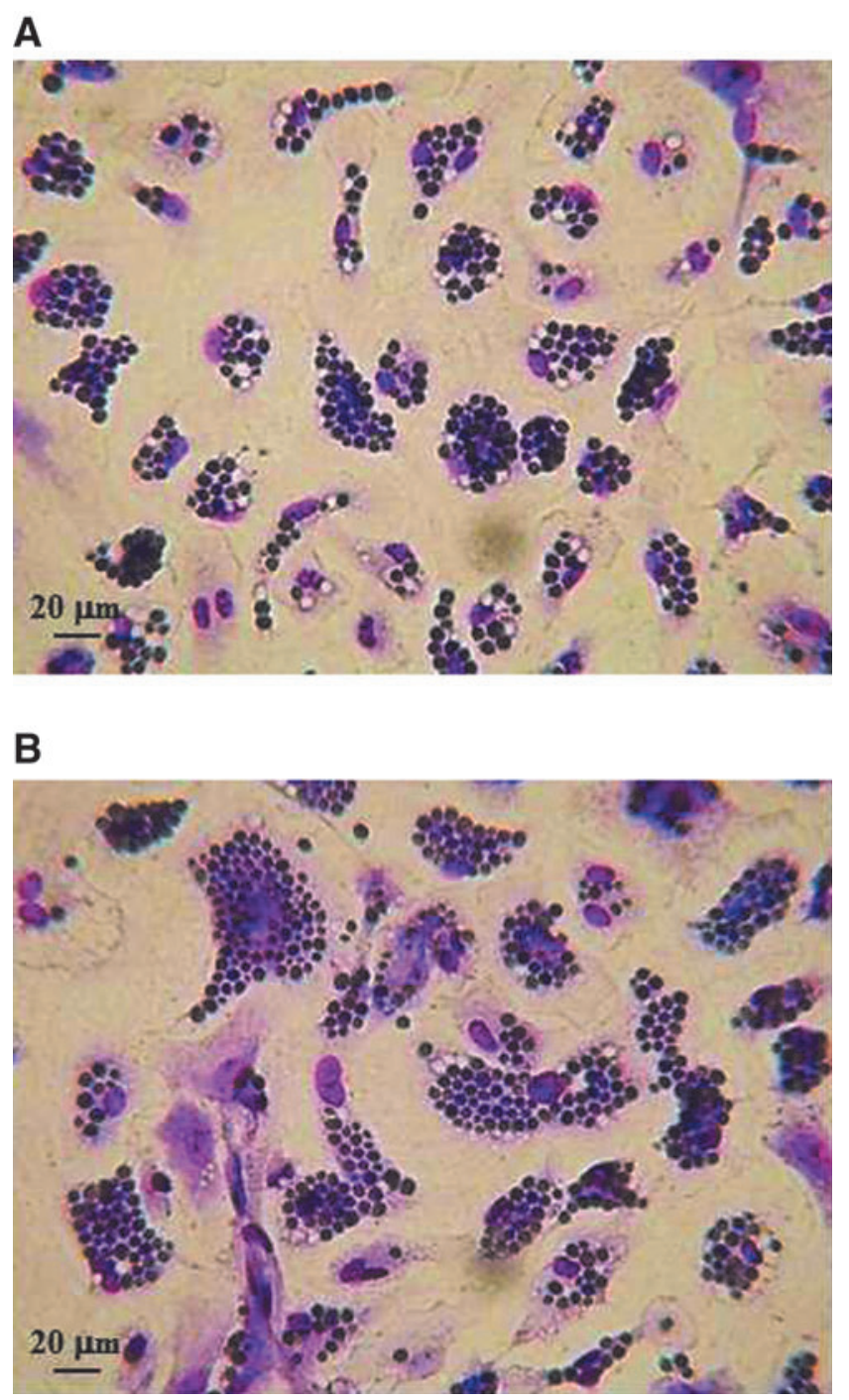

SUPPLEMENTARY FIG. S2. Representative photo of microglia (A) or microglia cocultured with MSCs (B) after phagocytosis of yeast cells. 

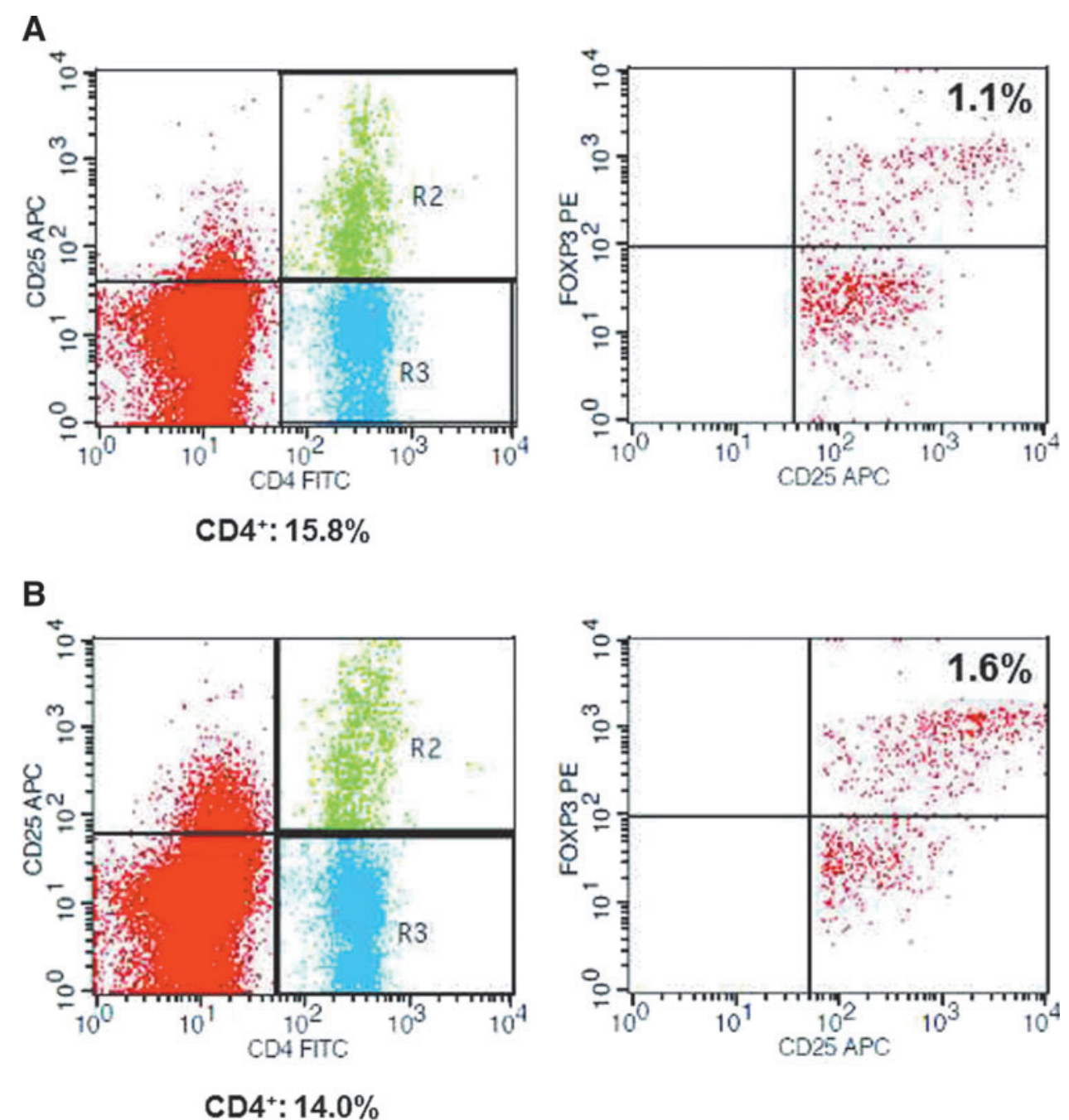

SUPPLEMENTARY FIG. S3. The percentage of $\mathrm{CD} 4{ }^{+} \mathrm{CD} 25^{\text {high }} \mathrm{Foxp} 3^{+}$regulatory $\mathrm{T}$ cells increased in the cocultures of MSCs and microglia. Representative dot plots of ovalbumin-specific CD4 ${ }^{+}$T cells for CD25 and Foxp 3 markers by flow cytometry in the presence of MGs (A) or microglia + MSCs (B). 


\section{AUTHOR QUERY FOR SCD-2014-0088-VER9-HEGYI_1P}

AU1: Please note that gene symbols in any article should be formatted as per the gene nomenclature. Thus, please make sure that gene symbols, if any in this article, are italicized.

AU2: Please review all authors' surnames for accurate indexing citations.

AU3: Ref. 27 has been deleted as it was a duplicate of Ref. 12, and Ref. citations in the text have been renumbered accordingly. Please check.

AU4: Please expand NK and RT.

AU5: "see below" and "see above" are imprecise. Please mention the exact section.

AU6: No colored lines are found in Figure 1. Please check.

AU7: Labels are mentioned in Figures 3-5, but they are not explained in the figure legend. Please check. 